\title{
EL «LIBRE DE LA MENESCALIA» DE MANUEL DIES: DE ESPEJO DE CABALLEROS A MANUAL DE ALBÉITARES*
}

\author{
Lluís Cifuentes y Carmel Ferragud \\ Depto. de Historia de la Ciencia, Institución Milà i Fontanals, CSIC. \\ Egipcíaques, 15, - 08001 Barcelona (España)-1luiscc@bicat.csic.es - carmelf@ctv.es
}

Preareu a mi, qui en temps antic preàveu

AUSIÀS MARCH, XXV, 5

\section{RESUMEN}

En este trabajo se exponen y ordenan los conocimientos actuales sobre un libro de albeitería y su autor: el Libre de la menescalia de Manuel Dies, mayordomo de Alfonso V (IV) el Magnánimo, rey de Aragón. Se reivindica el valor de la obra - frecuentemente rechazado- destacando el importante papel que jugó en el proceso de institucionalización del arte de la albeitería, un papel que se puso de manifiesto en la significativa evolución de su público, y se señala el compromiso activo del autor en ese proceso. Asimismo, se destaca la importancia de la obra dentro del interesante marco de la producción científica medieval en catalán, y su difusión tanto en esta lengua como en sus traducciones al francés y al castellano. Una obra que, gracias a la imprenta, llegó a convertirse (en catalán y sobre todo en castellano) en el principal libro de veterinaria de la Edad Media tardía y del Renacimiento hispánicos.

* Este trabajo expone resultados parciales de un proyecto de investigación financiado por la UE (Programa Capital Humano y Movilidad) y el MEC (Programa para la Incorporación de Doctores y Tecnólogos a Grupos de Investigación en España), a cargo del primero de los firmantes, y de la tesis doctoral en curso de realización, con una beca del PFPI del MEC, del segundo de nosotros. El contenido de este trabajo fue presentado brevemente en el XVI Congresso di Storia della Corona d'Aragona: Celebrazioni Alfonsine (Napoli, 18-24 sett. 1997). Deseamos expresar nuestro especial agradecimiento a Lola Badia (Universitat de Girona), Ricardo Campos (Centro de Estudios Históricos, CSIC), Luis Garcia Ballester (Universidad de Cantabria), M. ${ }^{a}$ Dolores González-Ripoll (Centro de Estudios Históricos, CSIC), Anna Gudayol (Biblioteca de Catalunya), Enric Guinot (Universitat de València), David Igual (Universitat de València), David Nirenberg (Rice University), Martí Pumarola (Universitat Autònoma de Barcelona), Jaume Riera i Sans (Arxiu de la Corona d'Aragó) y Pinuccia Simbula (Università di Sassari).

Abreviaturas: $\mathrm{ACA}=$ Arxiu de la Corona d'Aragó (Barcelona); $\mathrm{ACP}=$ Arxiu del Col-legi del Patriarca (Valencia); ARV = Arxiu del Regne de València (Valencia). 


\section{LLUÍS CIFUENTES Y CARMEL FERRAGUD}

\section{SUMMARY}

The article sets forth the state of the question concerning a medieval equine veterinary manual and its author: the Libre de la menescalia of Manuel Dies, majordomo of Alfonso V (IV) the Magnanimous, king of Aragon. The authors reassert the value of the work, which has often been denied, highlighting the important role it played in the process of institutionalization of the art of equine medicine, a process in which the author of the work played an active part. This role is evident in the work's developing audience. At the same time, the article highlights the work's importance within the interesting field of medieval scientific writing in Catalan, as well as exploring the work's dissemination both in Catalan, and in French and Spanish translations. Such was the work's importance that, thanks to the invention of printing, it became (in Catalan and above all in Spanish) the principal book of veterinary medicine in the hispanic world of the late Middle Ages and the Renaissance.

Bajo el reinado de Alfonso el Magnánimo, y posiblemente a instancias del propio monarca, fue escrito uno de los tratados de albeitería más importantes, y, sin duda, el más destacado de entre los que circularon en catalán: el Libre de la menescalia de Manuel Dies. Un tratado que fue también, en su traducción castellana, el primer libro de veterinaria que llegó a las prensas de los editores en la Península Ibérica ${ }^{1}$, reeditándose con frecuencia hasta mediado el siglo XVI.

\section{MANUEL DIES, CONSEJERO Y MAYORDOMO DEL MAGNÁNIMO}

Manuel Dies, noble valenciano de ascendencia aragonesa, fue señor de la villa de Andilla, en los Serranos de Valencia limítrofes con Aragón. A pesar de que formó parte

1 En los manuscritos medievales y en los impresos en catalán su nombre aparece de tres formas diferentes: Díez, Dieç y Dies. Entendemos que esta última forma es la que mejor refleja la vida de personajes como éste, y su integración en la sociedad valenciana de la época, que fue puesta de manifiesto por copistas, escribanos e incluso por ellos mismos, adaptando el apellido original de la familia (en este caso, sin duda, Díez) a la lengua del país (siendo las formas Dieç, en ortografía antigua, y Dies, equivalentes); sin dejar Valencia, a parte de los numerosos Llopis y Peris, un caso paralelo fue el del médico Lluís Alcanyís (y no Alcañiz), autor de un Regiment preservatiu e curatiu de la pestilència (ca. 1490) y titular de la primera «cadira de medicina e cirurgia» de la Universidad de Valencia. La forma Díaz, utilizada con frecuencia por la crítica española, tiene su origen en las ediciones de la traducción castellana de los siglos XV y XVI, mientras que la traducción francesa mantuvo Díez. Ninguno de los mss., ediciones o documentos que hemos podido consultar incluye el apellido de Calatayud con el cual aparece en buena parte de la bibliografía disponible desde que le fue atribuido (haciendo una larga genealogía de la que fue su esposa) por SAMPER, H. de (1669), Montesa ilustrada: Origen, fundación... héroes y varones ilustres de la... religión militar de $N$. S. Santa María de Montesa y San George de Alfama, Valencia, vol. 2, p. 591.a.

Sobre los albéitares y la albeitería en la Corona de Aragón, véase en general CIFUENTES, Ll., FERRAGUD, C., y GARCIA BALLESTER, L. (1998, en prensa), «Els menescals i l'art de la menescalia' a la Corona d'Aragó durant la Baixa Edat Mitjana», en Actes del IV Col-loqui d'Història Agrària: Història de la ramaderia i la veterinària als Països Catalans (Barcelona-Vic-Vilafranca-Girona, 20-24 Maig 1997). 


\section{EL «LIBRE DE LA MENESCALIA» DE MANUEL DIES}

de la nobleza urbana de Valencia, en estrecho contacto con las alianzas y bandos que caracterizaron la vida de la ciudad durante el Cuatrocientos, nos inclinamos a creer que nunca llegó a comprometerse personalmente en ellos ${ }^{2}$. De hecho, aunque parece que su familia había sido aliada de los Centelles, en 1411 le encontramos formando parte del parlamento urgelista reunido por sus enemigos, los Vilaragut, en Vinaròs durante el conflicto sucesorio. A lo largo de aquel año, los urgelistas valencianos fueron liquidados en la batalla de Morvedre y forzados a unirse a sus antagonistas: Manuel Dies fue uno de los seis embajadores que, en representación del reino de Valencia y junto con los compromisarios propios, asistieron al Compromiso de Caspe (1412) que, tras la muerte de Martín el Humano, dio la Corona de Aragón a Fernando de Antequera, padre del Magnánimo ${ }^{3}$. Poco más tarde, Alfonso lo convirtió en uno de sus mayordomos, administradores de la Casa del rey en todos los aspectos materiales, con autoridad, entre otros, sobre los caballerizos y los albéitares, y que formaban parte del consejo del monarca ${ }^{4}$. Durante estos años, al menos en dos ocasiones, fue uno de los barones del reino

2 Las fuentes clásicas para la biografía de Manuel Dies se encontrarán en RIBELLES COMÍN, J. (1915), Bibliografía de la lengua valenciana, Madrid (reimpr. facs. Nendeln-Liechtenstein, 1969), vol. 1, pp. 14243; SANZ EGAÑA, C. (1941), Historia de la veterinaria española: albeitería, mariscalería, veterinaria, Madrid, pp. 99-101; DUALDE PÉREZ, V., «Vinculación de la vida y obra de Mossen Manuel Dieç al reino de Valencia», I Jornadas Nacionales de Historia de la Veterinaria (Madrid, 29-30 junio 1995), después incluido en IDEM (1998), Historia de la albeytería valenciana, Valencia, pp. 258-60. Los datos ya conocidos, y muchos otros de inéditos, han sido sistematizados por BALDAQUí, R., y BALDAQUí, J. M. (1993), «A l'entorn de la biografia de Jordi de Sant Jordi: un document inèdit», en ALEMANY, R., FERRANDO, A., y MESEGUER, L. B. (eds.), Actes del novè col-loqui internacional de llengua i literatura catalanes (AlacantElx, 9-14 se setembre de 1991), Barcelona, vol. 1, pp. 257-71.

3 ZURITA y CASTRO, G. (1585 y 1610), Anales de la Corona de Aragón, Zaragoza, ed. CANELlas LÓPEZ, A. (Zaragoza, 1967-1977 y 1985), lib. XI, caps. 50 y 88. Sobre el posicionamiento del linaje en las bandosidades valencianas del Trescientos, véase CARRERES i ZACARÉS, S. (1930), Notes per a la història dels bandos de València, Valencia, pp. 40 y ss. y 56 y ss. (bando entre Jaume Dessoler y Gonçalvo Dies, bastardo, a partir de 1396), passim; y NARBONA VIZCAíNO, R. (1988-1989), «Los Rabassa, un linaje patricio de Valencia medieval», Anales de la Universidad de Alicante: Historia Medieval, 7, 111-36, en las pp. 120-21.

4 Así se identifica él mismo en el prólogo del Libre de la menescalia, y así le denomina Alfonso en 1421 y en 1424 (véase la nota 6). Efectivamente, fue uno de los nueve mayordomos que figuran en la lista general de personal de la corte impuesta al joven monarca hacia 1416 o 1417 en substitución de los castellanos que hasta entonces le habían rodeado (ACA, C, Vària 29, f. A-5 y B-6v), lista en la cual también encontramos a Antoni Ricard entre los médicos de física, Vidal Clotes y Guillem Costa como albéitares («menescals»), y el poeta Jordi de Sant Jordi entre los camareros. Sabemos que el rey «lo manà scriure en carta de ració e-1 reebre en lo dit offici» el 11 de junio de 1417, con una quitación, mientras acompañara a la corte, de 8 bestias de carga («de bast»), que se contaba a 2 sueldos per bestia y día, la propia de los «majordòmens nobles» (ibid., RP, MR, vol. 837, f. 26, junio 1417-junio 1418 [1152 sueldos barceloneses], transcrito en el Apéndice II). Cobró regularmente su quitación hasta 1419 incluido, año durante el cual, además, pasó a ejercer excepcionalmente como mayordomo principal «durant lo debat que mossèn Aymerich de Centelles e mossèn Berenguer d'Olms, majordòmens del dit senyor, havian sobre la prioritat de lur offici» (ibid., ff. 48, jul.-sept. 1418 [1200 sueldos barceloneses], y 62v, oct.-dic. 


\section{LLUÍS CIFUENTES Y CARMEL FERRAGUD}

convocados a cortes: formó parte del brazo militar de las cortes de Valencia de 14171418 y (como procurador de Federico de Aragón, conde de Luna, nieto del rey Martín) asistió a las de 1428; no aparece, en cambio, en la larga nómina de los convocados a las cortes de 1443-1446, fechas en que, si no había fallecido ya, debía tener sin duda una edad avanzada 5 .

Manuel Dies acompañó al rey en la expedición italiana de 1420-1423, durante la cual entró con él en Nápoles, y en remuneración por sus servicios, le fue concedida la primera alcaidía que quedara vacante en el reino de Valencia, más la del castillo de Alpuente - también en los Serranos-, ésta con facultad de cederla a su hijo. Finalmente, a la muerte del caballero y poeta Jordi de Sant Jordi, asumió la bailía y alcaidía del castillo y de la Vall d'Uixó (1424), que éste había ocupado 6 , y la retuvo en los

1419 [1440 sueldos barceloneses]; y vol. 937, ff. 2 [oct.-dic. 1418] y 22 [enero-marzo 1419]). Frecuentemente, sin embargo, aunque figura en la lista de mayordomos reales, no ejerció sus funciones (ibid., reg. 937 , ff. $46,72,98,123$ y 147 , diversos períodos en los años 1419 y 1420).

Sobre las tareas de los mayordomos reales, véase el capítulo Dels majordòmens en PEDRO IV (III) El CEREMONIOSO, Ordinacions fetes per lo molt alt senyor En Pere Terç, rey d'Aragó, sobre lo regiment de tots los oficials de la sua cort, ed. por BOFARULL i MASCARÓ, P. de (1850), en la Colección de documentos inéditos del Archivo General de la Corona de Aragón [=CODOIN], Barcelona, vol. 5, pp. 7-266, en las pp. 11-18, que hemos reproducido en el Apéndice I. Sobre el origen y la vigencia de este código, véase WILlEMSEN, C. A. (1940), «Zur Genesis der Mittelalterlichen Hofordnungen mit besonderer Berücksichtigung der Leges Palatinae Jakobs II von Mallorca», Staatl. Akademie zu Braunsberg. Personal- und Verlesung-Verzeichnis ( $2^{\circ}$ trimestre), 3-40; SCHENA, O. (1983), Le leggi palatine di Pietro IV d'Aragona, Cagliari; y PÉREZ MARTínEZ, L., et al., eds. (1991), Jaume III rei de Mallorca: Lleis Palatines, Palma de Mallorca, 2 vols.

5 Furs e ordinations fetes per los gloriosos reys de Aragó als regnícols del regne de València (Valencia, 1482; reimpr. facs.: Valencia, 1977), pp. 463, 488 y 502; y Simó SANTONJA, V. L. (1997), Les corts valencianes, 1240-1645, Valencia, pp. 279, 299 y 311-12. Sin que ello implique ninguna participación por parte de Manuel Dies, debemos tener en cuenta aquí que uno de los fueros (fuero XI) aprobados por las cortes de 1417-1418 obligaba a los médicos a redactar las recetas «en aquell llenguatge en què l'especier qui les haurà a confegir les puga bé entendre» y disponía que los productos tóxicos tan sólo pudieran ser expedidos por los apotecarios autorizados por los jurados municipales y los «veedors de la dita art». Las cortes de 1428 decidieron (fuero XV) ampliar a los cirujanos la obligación del examen previo a la obtención de licencia para practicar, tal como ya era preceptivo para los físicos desde 1329.

6 Dies figura en la lista de nobles y caballeros que acompañaron a Alfonso en esta expedición, a la cual aportó cinco hombres de armas, publicada por CAPMANY i de MONTPALAU, A. de (1787), Ordenanzas de las armadas navales de la Corona de Aragón, aprobadas por el rey Don Pedro IV, año de MCCCLIV, Madrid, Apéndice II, pp. 17-22, en la p. 18.

En la fase corsa de la campaña, durante el sitio de Bonifacio, el Magnánimo prometió con carta patente a su mayordomo la primera alcaidía que quedara vacante en el reino de Valencia (ARV, C, reg. 31, f. 104, 27-11-1420, publicado por BALDAQUí y BALDAQUí [1993], pp. 259-60, y, ampliado y datado pretendidamente un año más tarde, en ibid., f. $114 \mathrm{v}$, y también en ibid., BG, Lletres i privilegis, IV, ff. 88v-89, publicado por los mismos autores, pp. 267-69, § 1). Un año más tarde, en Messina, el rey ratificó la promesa al «dilectus maiordomus noster», pero añadiéndole la alcaidía del castillo de Alpuente y dándole facultad para ceder ésta a su hijo Rodrigo o a otros herederos (ibid., C, reg. 31, f. 113, 16-061421, publicado por BALDAQUí y BALDAQUí [1993], pp. 263-64). El detentor de la alcaidía de Alpuente 


\section{EL «LIBRE DE LA MENESCALIA» DE MANUEL DIES}

años siguientes, pero no más allá de 1436 - fecha en que el castillo de Uixó fue enajenado e integrado a los dominios cedidos por el rey a su hermano, el infante Enrique. En efecto, inmediatamente después (1437) le documentamos en la ciudad de Valencia, comprometiéndose a arbitrar, junto con otros caballeros, el duelo entre Joanot Martorell y Joan de Montpalau?.

Actualmente, tenemos más información sobre sus vínculos familiares. Manuel Dies estuvo casado con Caterina de Vilanova, miembro de otro conocido linaje noble valenciano y, ella, con sangre real ${ }^{8}$. Su padre, Rodrigo Dies, navegó en corso desde antes de su mayoría de edad legal por los mares de Sicilia y de Cerdeña, bajo fianza del abuelo de Manuel, Rodrigo (1382). El hijo de Manuel y de Caterina, también llamado Rodrigo, posiblemente participó en la misma expedición italiana de 1420-1423, fue convocado a las cortes de Valencia de 1428, y heredó de su padre el señorío de Andilla, que vendió en 1458 a su hermano Manuel, quien no dejó descendencia masculina. De Rodrigo Dies conocemos actividades corsarias y también diversas composiciones líricas, alguna de ellas enmarcada en un diálogo poético con Bernat de Fenollar y Ausiàs March. El hijo de Rodrigo, el comendador de San Juan y escritor Ferrando Dies, convocó diversos certámenes literarios en Valencia (1482, 1486 y 1487). En la

\footnotetext{
se resistió, y Dies, desde Nápoles, tuvo que conseguir una nueva orden real, en la que el monarca le denomina «dilectus consiliarius et maiordomus noster» (ibid., f. 129, 20-12-1421, publicada en BALDAQUí y BALDAQUí [1993], p. 264). Con estas donaciones reales, Dies emprendió el retorno a Valencia «per donar recapte a sa casa» y para hacerlas efectivas, y así lo notificó el Magnánimo a su esposa, entonces lugarteniente general, y al gobernador y baile general de Valencia (ibid., f. 172v, 25-01-1423, publicada por BALDAQUí y BALDAQUí [1993], p. 266). Cuando se presentó la oportunidad de la Vall d'Uixó, Dies, «cavaller, habitador de la ciutat de València», la reclamó al baile general (ibid., BG, Lletres i privilegis, IV, ff. 88v-89v, 21-06-1424, publicada por BALDAQUí y BALDAQUí [1993], pp. 270-71, § 2), y le fue reconocida inmediatamente (ibid., C, reg. 24, f. 17, 12-07-1424, publicado por DUALDE PÉREZ [1997], \& 19, pp. 443-44).

Sobre Jordi de Sant Jordi como alcaide de la Vall, véase GARCIA i GARCIA, H. (1962), Notas para la historia de Vall de Uxó, La Vall d'Uixó, p. 58 y ss.; RIQUER, M. de, y BADIA, Lola (1984), Les poesies de Jordi de Sant Jordi, cavaller valencià del segle XV, Valencia, p. 50; y BALDAQUí y BALDAQUí (1993), pp. 258-59 y 270-71, § 2 .

7 Joanot Martorell acusó a su primo Joan de Montpalau de haber deshonrado a su hermana y le envió una carta de «requesta de batalla a ultrança»; Montpalau eligió como árbitros propios a los caballeros de Valencia Pere Pardo, Manuel Dies y Francesc Maça, en un largo litigio que acabó siendo juzgado por Enrique VI de Inglaterra y que nunca llegó al combate personal. Véase RIQUER, M. de (1972), «Las cartas de batalla de Joanot Martorell», en IDEM y VARGAS LLOSA, M., El combate imaginario: Las cartas de batalla de Joanot Martorell, Barcelona, § 8, pp. 70-73, y § 14, pp. 94-97; VILLALMANZO CAMENO, J., y CHINER GIMENO, J. J. (1992), La pluma y la espada: Estudio documental sobre Joanot Martorell y su familia, 1373-1483, Valencia, pp. 64-67, § 475, pp. 290-92, у § 484, pp. 300-02; у Villalmanzo CAMENO, J. (1995), Joanot Martorell: Biografía ilustrada y diplomatario, Valencia, $\S$ 675, pp. 419-20, y § 684, § 426-27.

8 SAMPER, H. de (1669), vol. 2, p. 591.a. Era hija de Francesc de Vilanova y de Elionor d'Aragó, descendiente ésta del infante Pedro, conde de Ribagorza y de las Muntanyes de Prades, hijo de Jaime II.
} 


\section{LLUÍS CIFUENTES Y CARMEL FERRAGUD}

misma segunda mitad del siglo XV documentamos a otro posible descendiente de Manuel Dies: el noble Gaspar Dies, que en 1465 poseía molinos en Valencia ${ }^{9}$.

De Manuel Dies interesa destacar aquí su preocupación por las quastiones naturales y su compromiso con la medicina animal o veterinaria (la albeitería, o «menescalia», en catalán), un compromiso que no fue tan sólo intelectual sino también, como podremos comprobar, de reforma social.

\section{EL «LIBRE DE LA MENESCALIA»}

Perfilada mejor su biografía gracias a nuevos datos documentales recientemente descubiertos y a un repaso más serio de las fuentes disponibles, hoy podemos situar y valorar más acertadamente su obra. Del mismo texto se deduce que fue escrito en tierras valencianas, muy probablemente mientras fue alcaide de la Vall d'Uixó. ${ }^{10} \mathrm{En}$ cuanto a su datación, los nuevos documentos obligan a retrasar la redacción del texto original, en catalán, a los años inmediatamente posteriores a la expedición italiana de 1420-1423, en lugar de hacerla depender como hasta ahora de la conquista de Nápoles de veinte años más tarde. Así pues, hay que situar la redacción muy probable-

9 Sobre el padre y el abuelo de Manuel Dies, véase SimBULA, P. (1993), Corsari e pirati nei mari di Sardegna, Cagliari, pp. 42, 48, 100 y 259. Su hijo Rodrigo avaló (1436) al caballero Jaume de Vilaragut en el armamento de la nave Santa Maria de Sent Antoni, y él mismo armó en corso (1439) el ballenero Santa Caterina, del que era propietario y patrón, con el aval del noble Pere Ladró, en el cual embarcaron dos albéitares (véase GUIRAL-HADZIIOSSIF, J. [1986], Valence: Port méditerranéen au XV siècle, 1410-1525, París [trad. esp.: Valencia, 1989], pp. 58, 162, 204 y 297-300 de la trad. esp.) Sobre la actividad literaria de éste y de su hijo Ferrando, véase CERDÀ RICO, F. (1778 [=1780]), Notas al Canto de Turia o noticias históricas de algunos poetas y escritores del Reino de Valencia, Madrid, pp. 326-27, 337-41, y árbol genealógico en las pp. 519-22; MARTí GRAJALES, F. (1927), Diccionario biográfico y bibliográfico de poetas de Valencia, Madrid, pp. 191-92 y 222; RIQUER, M. de (1964; reed. 1983), Història de la literatura catalana, Barcelona, vol. 3, pp. 280-83, 322, 375-79 y 393; y FERRANDO i FRANCÈs, A. (1983), Els certàmens poètics valencians del segle XIV al XIX, Valencia, pp. 385-86 y 774. La filiación de Rodrigo con respecto a Manuel Dies ha sido probada por BALDAQUí y BALDAQUí (1993), pp. 262-64 (véase la nota 6). Sobre Gaspar Dies, véase GUIRAL-HADZIIOSSIF, J. (1986), p. 318 de la trad. esp.

10 GASPARETTI, A. (1931), «Un trattato di Mascalcia del secolo XV in lingua catalana», Boletín de la Sociedad Castellonense de Cultura, 12, 289-335, en la p. 317 llegó a la conclusión de que «il trattato deve essere stato scritto in Catalogna, sebbene l'autore debba aver soggiornato per alcun tempo in Italia». Se basa en dos detalles del contenido: 1) la recomendación de llevar exvotos de cera a un santuario bajo advocación de Santa Quiteria como último remedio para los caballos mordidos por perros rabiosos (lib. I, cap. «A mordedura de ca rabiós»), proponiendo GASPARETTI su identificación con el que se encuentra en la Roca del Vallès pero ignorando la existencia del de Almassora, a unos $20 \mathrm{Km}$ de la Vall d'Uixò; y 2) la valoración que hace de la cebada «d'ací de regne de València» como demasiado fuerte, en comparación con la de «Cicília» (lib. I, cap. «Com se deu tenir cavall jove de edat de tres anys fins a sis»). Manuel Dies, como alcaide de la Vall d'Uixó, percibía 600 florines anuales sobre el grano importado de Sicilia (DUALDE PÉREZ, V., «Vinculación», p. [3]). 


\section{EL «LIBRE DE LA MENESCALIA» DE MANUEL DIES}

mente después de 1424 y en todo caso antes de $1436^{11}$. El Libre de la menescalia es la única obra conocida de Manuel Dies. Debemos descartar las atribuciones que alguna vez se le han hecho, basándose en anotaciones espurias y malas lecturas de textos presentes en algún manuscrito ${ }^{12}$.

Para la redacción de la obra, el autor se sirvió de dos de los mejores compendios de albeitería de su tiempo. El primero, su fuente principal, fue el Liber marescalcie del albéitar italiano Lorenzo Rusio, escrito en Roma en la primera mitad del siglo XIV para el cardenal Napoleone Orsini $(\dagger 1342)$. Este tratado, basado en los principales textos anteriores (y en la propia experiencia personal del autor), constituye el producto más acabado del arte de la albeitería en la Italia medieval, y alcanzó una importante difusión tanto en latín, como en diversos dialectos italianos (entre ellos el siciliano), en francés y en neerlandés; según parece, Fernando I poseyó un ejemplar iluminado de la traducción italiana de este tratado ${ }^{13}$. La segunda fuente de Manuel Dies fue el tratado anónimo castellano conocido como Libro de fecho de los cavallos,

11 BARBERÀ MARTÍ, F. (1914), «Un hematòleg valencià del sigle XV», en Actes, ponència i comunicacions del Primer Congrés dels Metges de Llengua Catalana celebrat a Barcelona en els dies 22, 23, 24 i 25 de juny de l'any MCMXIII, Barcelona, pp. 33-34, sugirió que su redacción debía haber tenido lugar a raíz de «la conquesta de Nàpols, feta en l'any 1423». Igualmente, LLEONART i ROCA, F. (1973), «Manel Dieç (14..?-?)», en CORDERO DEL CAMPILLO, M., et al. (dir.), Semblanzas veterinarias, León, vol. 1, pp. 13-15 (un texto, por otra parte, bastante desinformado), ya se había inclinado por datarlo entre 1430-1440. BALDAQUí y BALDAQUí (1993), p. 265, lo datan entre 1421 y 1423, durante la campaña italiana, basándose en la Introducción, como veremos falsa, de los impresos castellanos. Con los documentos descubiertos por Vicente DUALDE, debemos situarla antes de 1436 (véase la nota 56).

12 En los primeros folios del ms. 68 de la Biblioteca Universitària de Barcelona (mediados s. XV), que aparentemente perteneció al cronista, notario y archivero real Pere Miquel Carbonell (1434-1517), hay un índice escrito de la mano de éste en el cual atribuye a Manuel Dies los tratados presentes en el volumen: Libre de bons amonestaments (de Anselm Turmeda), Libre de la menescalia (de Manuel Dies), Libre dels aucells de caça, Capitols de l'Orde de la Gerra i el Grifó, Libre de banys e escubes e paladors d'altres coses per mundificar el cos de les dones e de la belesa de la cara e d'altres partides del cos [= Flors del tresor de beutat], Libre de totes maneres de confits, y Libre de totes maneres de potatges de menjar [= Libre de Sent Sovi] . Se trata de un ms. misceláneo, con textos de temas que podían interesar a un público lector de burgueses y nobles, muy similar al ms. 216 de la Biblioteca Universitària de Valencia (s. XV-1), pero en este caso el autor de la recopilación unificó todo el conjunto con rúbricas descriptivas del contenido del volumen y de cada tratado. Carbonell malinterpretó estas rúbricas, entendiendo erróneamente que Manuel Dies fue el autor de todos los textos, error que más tarde mantuvo Villanueva en su descripción del volumen (VILlanUEVA, J. [1851], Viage literario a las iglesias de España, Madrid, vol. 18, pp. 183-94), y que han repetido otros historiadores. Tampoco parece probable que Manuel Dies fuera el recopilador de los textos presentes en este manuscrito.

13 El texto latino y una de les versiones italianas fue editado por DELPRATO, P., y BARBIERI, L. (1867), La mascalcia di Lorenzo Rusio: volgarizzamento del secolo XIV, Bolonia, 2 vols. Véase la ficha bibliográfica de POULLE-DRIEUX, Y. (1966), «L'hippiatrie dans l'Occident latin du XIII' au XV'e siècle», en BEAUjouAn, G., POULle-DRIEUX, Y., y DuREAU-LAPEYSSONNIE, J.-M., Médecine humaine et vétérinaire à la fin du Moyen Âge, Ginebra-París, pp. 9-167, en las pp. 40-42, donde se da cuenta de la subasta del ejemplar de Fernando I de Aragón (=de Nápoles?) en Londres en 1961. 


\section{LLUÍS CIFUENTES Y CARMEL FERRAGUD}

una compilación realizada a partir de la Mulomedicina del dominico, obispo y médico norteitaliano Teodorico Borgognoni. Este último tratado muestra claramente ser obra de un médico por el sensible interés que manifiesta en la aproximación de la medicina y la albeitería, al hacer uso reiterado de la patología comparada hombreanimal. Para su redacción, Teodorico se había basado en la que también había sido la fuente principal de Lorenzo Rusio, el De medicina equorum del noble calabrés y «cavaller en la menescalia» del emperador Federico II, Giordano Ruffo, posiblemente el más difundido de los escritos de albeitería medievales, tanto en latín como en muchas lenguas vulgares ${ }^{14}$. Tanto el Libro de fecho de los cavallos como la obra de Ruffo circularon en catalán durante los siglos XIV y XV ${ }^{15}$. Hay que decir que la ceguera tradicional sobre la ordinatio partium como factor creativo en la compilación medieval ha provocado una valoración injusta de la obra de Dies. No comprendiendo este hecho, algunos historiadores han calificado a Dies de simple copista o traductor, y han menospreciado arbitrariamente su obra. Ciertamente, Dies copió de Rusio y del autor del Libro de fecho de los cavallos, pero en la misma medida en que éstos habían copiado de otros autores anteriores ${ }^{16}$.

14 Sobre cada una de estas obras, véase Poulle-DrieuX, Y. (1966), pp. 17-21 (Ruffo), 22-24 (Teodorico) y 29-30 (Libro de fecho de los cavallos). El anónimo castellano fue editado por SACHS, G. (1936), El libro de los caballos, tratado de albeitería del siglo XIII, Madrid (Revista de Filología Española, anejo XXIII). Sobre Ruffo véase también ZAHLTEN, J. (1971), «Die «Hippiatria» des Jordanus Ruffus: Ein Beitrag zur Naturwissenschaft am Hof Kaiser Friedrichs II», Archiv zur Kulturgeschichte, 53, 20-52; POUlle-DrieuX, Y. (1975), «Giordano Ruffo», en GIllisPIE, Ch. C. (dir.), Dictionary of scientific biography, Nueva York, vol. 11, pp. 600-01; PRÉVOT, B., ed. (1991), La science du cheval au moyen âge: Le «Traité d'hippiatrie» de Jordanus Rufus, París; y GAULIN, J.-L. (1994), «Giordano Ruffo et l'art vétérinaire», Micrologus, 2 [=Le scienze alla corte di Federico II (Erice, sept. 1990)], 185-98.

15 Se han editado sendas traducciones catalanas medievales del primero (Libre en feyt dels cavalls) y del segundo de los tratados citados (Libre de menescalia): GILI, J. (1988), Libre dels cavayls que compós Ypocràs: Manuscrit del segle XV, Oxford; IDEM (1985), Lo cavall: Tractat de manescalia del segle XV, Oxford. Hay que decir que, tanto del uno como del otro, en catalán circularon (y se han conservado) más versiones que las editadas; véase CIFUENTES, Ll. (en preparación), La medicina en català a la Baixa Edat Mitjana i el Renaixement: Catàleg de manuscrits i de primers impresos. Hay que repetir aquí que no se conserva ninguna traducción catalana de la Mulomedicina de Teodorico como se ha dicho erróneamente con frecuencia; el texto presente en el ms. Espagnol 212, ff. $93 \mathrm{v}^{\mathrm{a}}-109 \mathrm{v}^{\mathrm{a}}$, de la Bibliothèque Nationale de París es una versión en catalán de la obra de Ruffo y no de la del dominico italiano. Véase PoULLEDRIEUX, Y. (1966), pp. 20-21 y 23.

16 «Lo que no ha dicho ningún autor es que Díaz fué un copista, cuando más, mero traductor de un manuscrito más antiguo, probablemente escrito en latín o en italiano y puesto por él en catalán; este descubrimiento es muy moderno y le quita todo mérito científico a la obra, pero no le resta la primacía en nuestra bibliografía impresa» (SANZ EGAÑA, C. [1941], p. 99). Véanse también las conclusiones de FARAUDO DE SAINT-GERMAIN, Ll. (1949), «El texto primitivo inédito del 'Tractat de les mules' de Mossén Dieç», Boletín de la Real Academia de Buenas Letras de Barcelona, 22, 23-62, en las pp. 24-27; y de DuALDE PÉREZ, V. (1997), pp. 261-62. SANZ EGAÑA magnificó la influencia del Libro de fecho de los cavallos a la vez que ignoró totalmente la de la obra de Rusio (ibidem, pp. 101-02). Estas influencias 


\section{EL «LIBRE DE LA MENESCALIA» DE MANUEL DIES}

Manuel Dies estructuró su obra en dos libros, el primero de los cuales y principal está dedicado a los caballos (Libre de cavalls) y el segundo, y más original del autor, a las mulas (Tractat de les mules). A lo largo de estos dos libros, presenta un amplio compendio de la hipología (reproducción, doma, mantenimiento, morfología exterior del caballo, colores y señales por los cuales se reconoce a un buen animal tanto en la paz como en la guerra, frenos), y de la hipiatría (la terapéutica aplicable a los equinos, con una breve descripción de las enfermedades seguida de la exposición de sus remedios), completando la obra con unas nociones de dietética y de cirugía, que se justifican en caso de heridas de guerra. A parte de todo esto, la obra va acompañada de material complementario que, en forma de ilustraciones, permite un rápido acceso a los conocimientos necesarios sobre la anatomía del animal, las partes donde se manifiestan las enfermedades más significativas, los puntos donde deben realizarse las sangrías, los astros que rigen cada miembro del cuerpo, un calendario astrológico con indicación de los días favorables y desfavorables para la sangría y la medicación, la construcción y el uso (terapéutico o no) de un gran número de frenos, o la demostración gráfica de la aplicación de determinados tratamientos. Este material complementario, si bien no falta totalmente en ninguno, varía según los manuscritos y las ediciones. Por esta razón, por ahora, sin un estudio más profundizado (que no constituye el objeto de esta nota), se hace difícil saber cual es original y cual añadido en el proceso de divulgación de la obra ${ }^{17}$.

El contenido compendiado, presentado de forma fácilmente accesible, alejado de la pesadez y del desorden de otros escritos del mismo género, y en lengua vulgar, garantizó al Libre de la menescalia de Manuel Dies un éxito extraordinario. De su enorme difusión dan fe el gran número de manuscritos catalanes cuatrocentistas conservados —que hace de él el texto científico medieval en catalán con más testimonios existentes- ${ }^{18}$ las adaptaciones de su texto efectuadas por otros autores de al-

\footnotetext{
fueron claramente demostradas, con comparaciones textuales, por SACHS, G. (1936), p. xxi, y por FARAUDO DE SAINT-GERMAIN, Ll. (1949), pp. 51-52.

17 Véase, en general, SANZ EGAÑA, C. (1941), pp. 102-03; Poulle-DrieuX, Y. (1966), pp. 36-38; DUALDE PÉREZ, V. (1997), pp. 262-67; y CIFUENTES, Ll. (en preparación), La medicina en català. GASPARETTI, A. (1931), en las pp. 294-314, reproduce la tabla de los capítulos de uno de los mss. de Palermo (véase la nota siguiente); y ÁlvAREZ MÁRQueZ, C. (1991), Libro de Albeytería. Manuel Díaz. Estudio y transcripción de - Llibre de Menescalia de Manuel Díaz (Ms. 5-4-46 de la Biblioteca Capitular y Colombina de Sevilla), Sevilla, da una edición facsímil y la transcripción correspondiente de la tabla del Libre de cavalls, de las notables ilustraciones y de dos folios sueltos del ms. de Sevilla (véase la nota siguiente).

18 En Barcelona, Biblioteca de Catalunya, ms. 1661, año $1502(*)$, y Biblioteca Universitària, ms. 68, mediados s. XV (*); en Catania, Biblioteca Universitaria, ms. 80, s. XV; en New Haven, Yale University Library, ms. General 454, mediados s. XV; en Palermo, Biblioteca Comunale, ms. 2Qq E 117, mediados s. XV, y Biblioteca Centrale della Regione Siciliana, ms. V-E 17, mediados s. XV; en París, Bibliothèque Nationale, ms. Esp. 215, s. XV (*); en Sevilla, Biblioteca Colombina, ms. 5-4-46 bis y fragmentos del mismo en el ms. 5-4-46, s. XV (*); y en Valencia, Biblioteca Universitària, ms. 624, mediados s. XV (*),
} 
beitería poco después de su redacción y las traducciones al francés, al castellano y al gallegoportugués realizadas también antes de acabar el siglo XV. A diferencia de la traducción francesa, aparentemente llevada a cabo a partir del catalán y vinculable a la presencia gala en el reino de Nápoles durante la segunda mitad del siglo XV y de la gallegoportuguesa ${ }^{19}$, en castellano alcanzó una gran difusión sobre todo gracias a la imprenta. En esta última lengua se publicaron dos traducciones diferentes: una primera del caballero aragonés Martín Martínez de Ampiés, impresa en dos ocasiones a partir de la princeps de Zaragoza de 1495, y otra, declaradamente «emendada e corregida», impresa en Valladolid en 1500 y al menos en nueve ocasiones más en diversas ciudades de la Corona de Castilla y de Aragón durante el siglo XVI ${ }^{20}$. La

ms. 630, s. XV $\left(^{*}\right)$, y ms. 631, mediados s. XV (*), y Biblioteca Valenciana, ms. 137, s. XV (*). Los que llevan la señal $\left(^{*}\right)$ los hemos consultado directamente. Algunos autores citan dos mss. más, uno en el convento de los carmelitas descalzos de Sevilla (RIBELLES Comín, J. [1915], vol. 1, p. 160) y otro en la Biblioteca Vaticana (ANTONIO, N. [1696], Bibliotheca Hispana Vetus, sive Hispani scriptores qui ab Octaviani Augusti aevo ad annum Christi MD floruerunt, Roma, vol. 2 [reimpr.: Madrid, 1788 y 1997], pp. 277 $78, \S 470-472$; véase la nota 33), noticias que de momento no hemos podido confirmar.

19 Manuscritos en París, Bibliothèque Nationale, fr. 2002, y Montpellier, École de Médecine, 266. Véase POUlle-DrieuX, Y. (1966), p. 37; y PRÉVOT, B., y RiBÉMONT, B. (1994), Le cheval en France au Moyen Âge. Sa place dans le monde médiéval; sa médecine: l'exemple d'un traité vétérinaire du XIVe siècle, la "Cirurgie des chevaux», Orléans, pp. 342-44, donde se reproduce la versión francesa del prólogo de Manuel Dies a partir del primero de estos mss., datado del s. XV. Previa verificación de la transcripción, gentilmente realizada por Anna Gudayol (Biblioteca de Catalunya), la ofrecemos en el Apéndice VIII. Hemos tenido conocimiento de la existencia de una traducción gallegoportuguesa cuatrocentista poco antes de entregar el texto definitivo de este artículo, sin tiempo para ofrecer más información, como sería nuestro deseo.

20 Las ediciones castellanas (Libro de albeytería) que se conocen son las siguientes: Zaragoza, Pablo Hurus, 1495; Zaragoza, [Jorge Coci, Leonardo Hutz y Lope Appentegger], 1499; Valladolid, Juan de Burgos, 1500; Toledo, sucesores de Pedro Hagembach, 1507 y 1511; Toledo, Juan de Villaquirán, 1515; Valladolid, Diego Gumiel [o Zaragoza, Jorge Coci], antes de 1524; Burgos, Juan de Junta, 1530; Jaén, Juan Varela de Salamanca, 1534; Salamanca, Juan de Junta, 1544 y (quizás del mismo impresor) 1545; y Zaragoza, Diego Hernández, 1545. La edición de antes de 1524 (uno de los ejemplares conocidos fue adquirido en Valladolid por Fernando Colón en esa fecha) no tiene pie de imprenta; contra las hipótesis de los historiadores de la imprenta zaragozana, AGUILó reconoció los tipos de Diego Gumiel, activo en Valladolid entre 1503 y 1512 . Algunos autores, frecuentemente por confusión o por el hecho de consultar ejemplares mutilados, citan aún otras ediciones cuya existencia dista mucho de estar demostrada (Zaragoza, 1498; Barcelona, 1505; Burgos, hacia 1532; Burgos, hacia 1550; Toledo, 1571; Barcelona, 1571; Madrid, 1580). Véase Ribelles COMín, J. (1915), § 60-65, 67, 70, 72-76; AGUILÓ i FuSTER, M. (1923), Catálogo de obras en lengua catalana impresas desde 1474 hasta 1860, Madrid (reimpr. facs.: Barcelona-Sueca, 1977), § 1939-1940; PALAU i DULCET, A. (1951), Manual del librero hispano-americano, Barcelona, vol. 4, § 73703-73711; PALAU i CLAVERAS, A. (1973), Bibliografía hispánica de veterinaria y equitación anterior a 1901, Madrid, § 1495 (núms. 1-8, 10 y 13-16); LÓPEZ PIÑERO, J. M. ${ }^{a}$, et al. (1984), Los impresos científicos españoles de los siglos XV y XVI: Inventario, bibliometría y thesaurus, Valencia, vol. 2, § 451-456, 458 y 461-464; RIERA i SANS, J. (1989), «Catàleg d'obres en català traduïdes en castellà durant els segles XIV i XV», Segon Congrés Internacional de la Llengua Catalana, Valencia, vol. 8, pp. 699-709, en la p. 706; y Catálogo colectivo del patrimonio bibliográfico español 


\section{EL «LIBRE DE LA MENESCALIA» DE MANUEL DIES}

imprenta también lo divulgó en catalán, en dos ediciones (Barcelona, 1515 y 1523), pero éstas no se basaron en el texto catalán original sino en la ya muy difundida versión castellana, de la que ofrecen una retraducción al catalán ${ }^{21}$. Avanzado el siglo XVI, el Tractat de les mules fue objeto de una nueva traducción al castellano, a cargo del médico de Talavera Alonso Suárez, pero realizada a partir de esta retraducción catala$n^{22}$. Un éxito, en suma, que lo convirtió en el principal libro de albeitería de la Edad Media tardía y del Renacimiento hispánicos. Con semejante difusión tan bien documentada, se entiende poco que no tuviera ninguna influencia en la literatura hipiátrica tal como, precipitadamente y sin mediar estudio alguno, se ha llegado a afirmar; más bien parece haber pruebas fehacientes en sentido contrario ${ }^{23}$. Como veremos, el libro

(http://www.mcu.es/ccpb), «Díez Manuel». Se conservan copias manuscritas del Libro de albeytería de las mulas en Madrid (Biblioteca de la Real Academia de la Historia, Col. San Román 47, s. XVI) y Barcelona (Biblioteca de Catalunya, ms. 864, ss. XV-XVI). Nicolás ANTONIO, en el lugar ya citado, aseguró haber visto dos mss. castellanos aparentemente completos, uno en la Biblioteca de la Catedral de Sevilla (=Colombina) y otro en la del conde-duque de Olivares.

Sobre el impacto de la imprenta, resulta muy ilustrativo el comentario final del editor de 1499: «Gozen los lectores de nuestros días y los que vinieren de bien tamaño como es el arte de la emprenta, porque parece una maravilla por Dios revelada para que hayan lumbre los ciegos de la ygnorancia, pues muchos primero andavan turbados en las tiniebras por mengua de libros no instruydos en la doctrina de los costumbres de la virtud y mal enseñados en la muy sancta y sagrada Scriptura, la qual bien saber es <tan> provechosa como necessaria, y pueden agora sin mucho trabajo, con pocos gastos, haver tanta parte como el ingenio de cada uno tomar pudiere, y no en ésto sólo es provechosa, empero ahún para los libros de la medicina, muy necessaria en las dolencias de nuestros cuerpos, muy corruptibles, como en el arte de albeytería» (transcripción paleográfica de CORTIJO, A., y GóMEZ MORENO, Á. [1992], en MARCOS MARÍN, F., et al. [dir.], Archivo digital de manuscritos y textos españoles [=ADMYTE], Madrid, disco 1, núm. 32; de aquí hemos extraido el prólogo de Martín Martínez de Ampiés que reproducimos en el Apéndice IX). Martínez de Ampiés fue diputado del reino de Aragón (1480), y hombre de reconocidas cualidades políticas y militares.

21 Pueden verse ejemplares de la edición de 1515, realizada por Joan Rosembach, en Barcelona (Biblioteca de Catalunya, 6-V-20/26, fragmentario), Madrid (Biblioteca Nacional, R-14471 y R-10833), Ripoll (Biblioteca Lambert Mata, R-107, R-108 y R-109, todos ellos fragmentarios) y Valencia (Biblioteca Universitària, R-1/228). Hay ejemplares de la edición de 1523, de Dimes Bellestar y Joan Giglo, en Barcelona (Biblioteca de Catalunya, Res. 763-8, incompleto, y 3-VI-8/40, un fragmento) y Madrid (Biblioteca Nacional, R14471, un fragmento). Véase RIBELLES COMÍN, J. [1915], § 66, 68-69 y 71; AGUILÓ i FUSTER, M. (1923), § 1937-1938; PALAU i DULCET, A. (1951), § 73698-73702; PALAU i ClAVERAS, A. (1973), § 1495 (núms. 9, 11 y 12); LÓPEZ PIÑERO, J. M. §, et al. (1984), § 457 y 459-460; Catálogo colectivo, «Díez Manuel»; y Catàleg col-lectiu del patrimoni bibliogràfic (http://www.gencat.es/bc/virtua2/catalan), «Díez Manuel».

22 ALONSO SUÁREZ (1564), Recopilación de los más famosos autores griegos y latinos que trataron de la excelencia y generación de los cavallos, y assimismo cómo se han de doctrinar y curar sus enfermedades, y también de las mulas y su generación, agora nuevamente transladados de latín en nuestra lengua castellana..., Toledo, Miguel Ferrer. Véase SANZ EGAÑA, C. (1941), pp. 108-11.

23 Tanto SANZ EgAÑa como DUALDE PÉREZ niegan la influencia de la obra. Sin embargo, ya Ribelles CoMín, J. (1915), vol. 1, pp. 159-60, citó, además de la obra de Alonso Suárez (1564), el Libro de alveitería del mexicano Juan Suárez de Peralta (segunda mitad del s. XVI). LLEONART i RoCA, F. (1973), pp. 13-14, cita obras de albeitería alemanas, italianas y francesas: el aparentemente anónimo 


\section{LLUÍS CIFUENTES Y CARMEL FERRAGUD}

de Dies respondió a un momento concreto de la historia de la albeitería, y lo hizo con eficiencia, cosa que algunos autores no han llegado a comprender ${ }^{24}$.

Debido a esto, quizás, el éxito y la trascendencia de la obra no se han correspondido con el favor de la crítica moderna. A parte del menosprecio de algunos historiadores, todas las listas de manuscritos y de impresos que se han ofrecido hasta el momento contienen lagunas e inexactitudes en una u otra medida, debidas básicamente a la limitada consulta de originales. Por otro lado, aunque Lluís Faraudo publicó uno de los manuscritos del Tractat de les mules, aún no disponemos de ninguna edición crítica del conjunto de la obra original de Manuel Dies, y ésto muy a pesar de su gran importancia para la historia de la medicina veterinaria, la lingüística y la filología catalanas medievales ${ }^{25}$.

En el texto original catalán, Manuel Dies no atribuye su obra a un encargo directo del rey Alfonso, ni tampoco se la dedica. Más bien da a entender que el libro es fruto de una iniciativa personal de quien no deja de identificarse como mayordomo del monarca: «yo, Manuel Diez, majordom del molt alt e poderós príncep e victoriós senyor don Alfonso, rey d'Aragó et cetera, vull fer un libre de cavalls...» Nada más ${ }^{26}$. El supuesto encargo directo del rey aparece (no sabemos si inventado por los editores) en las ediciones castellanas del Quinientos, en estos términos:

Como a mi, don Manuel Díaz, natural de la muy noble et leal cibdad de Çaragoça de
Aragón, me hiziesse Dios tanta gracia y merced que fuesse mayordomo de aquel ilustríssimo
et muy poderoso el rey don Alfonso de Aragón... el qual... aquel reino de Nápoles toviendo

Volger Koijtre (Nuremberg, 1573), el Dell'anatomia e dell'infirmità del cavallo, de Carlo Ruini (Bolonia, 1598, reimpr. durante los ss. XVII y XVIII) y la Hippostologie, c'est-à-dire, discours des os du cheval, de Jean Hervard (París, 1599).

24 A pesar de sus comentarios presentistas, una notable excepción, por temprana, fue Juan MORCILlo OlAlla. En su Bibliografía veterinaria española (Xàtiva, 1883), uno de los primeros intentos serios modernos de sistematizar la historia de la profesión, ya vislumbró cual fue la importancia de la obra de Manuel Dies: «No se puede negar que la obra de Díaz contiene muchas puerilidades relativas a la higiene y terapéutica, debidas a la época en que escribió, y que nada tiene de extraño; pero tampoco se puede negar la gran importancia del libro que nos ocupa, y que su autor comprendió lo interesante que en aquel entonces era el libro que se le mandó confeccionar para los albéitares de su tiempo, que carecían de obras de esta índole para instruirse... en él se advierte un método y orden singular, del que suelen carecer las obras de tiempo posterior» (ibidem, pp. 56-57). Juicio que ya había sido apuntado anteriormente por Ramón LLORENTE LÁZARO, Compendio de la bibliografía de la veterinaria española... (Madrid-SantiagoValparaíso-Lima, 1856), p. 29:

«Es de notar en esta obra, no tanto la importancia de las ideas como el método y claridad con que están espuestos».

25 FARAUdo De SAINT-Germain, Ll. (1949), reproduciendo el texto del ms. 68 de la Biblioteca Universitària de Barcelona. Tal como ha indicado recientemente DUALDE PÉREZ, V. (1997), p. 266, la nomenclatura utilizada en la obra continúa vigente, en muchos casos, en el lenguaje popular. Tenemos prevista la edición crítica del tratado en un futuro próximo.

26 MANUEL DIES, Libre de la menescalia, lib. I, prólogo. Véase el Apéndice III. 


\title{
EL «LIBRE DE LA MENESCALIA» DE MANUEL DIES
}

\begin{abstract}
cerco encima de aquellas villas y cebdades con mucha gente... et cada día andava entre sus gentes mirando los heridos et enfermos... veyendo que algunos cavallos de sus gentes en muchas partes se morían, et como fue informado que a las vezes era causa no poder haver tantos albéytares como necesario eran en tan grandes exércitos como este animoso rey tenía, mandó a mi, el dicho mayordomo, que hiziesse ayuntar todos sus albéytares et que ordenassen un libro de todas las condiciones de los cavallos y enfermedades que en ellos acaecer podiessen, et con quantas curas et remedios sanarlos pudiessen. E assí, por su mandado, hize llamar a todos los mejores albéytares que hallarse pudieron et ordenaron este libro llamado Albeytería... E después que este libro fue copilado et fecho, mandó su Alteza dar traslados dél a quantos los quisiessen ${ }^{27}$.
\end{abstract}

Ninguna de las dos ediciones de la retraducción catalana incluye este más que sospechoso pasaje, y sí, en cambio, un Prohemi, escandalosamente apócrifo, según el cual Manuel Dies en persona habría vivido como para dedicar la obra a Alfonso de Aragón, arzobispo de Zaragoza (1478-1520) ${ }^{28}$. Como hemos dicho, ni uno ni otro hecho (este último por imperativos cronológicos evidentes) figuran en ninguno de los manuscritos catalanes que hemos podido consultar ${ }^{29}$. La divergencia entre la versión catalana original conservada en los manuscritos y la que contienen los impresos de

27 Hemos podido comprobar que aparece así, al menos, en las ediciones de Toledo de 1507, 1511 y 1515, de Valladolid [o Zaragoza] de antes de 1524, de Burgos de 1530, y en la de Zaragoza de 1545, y es muy probable que este pasaje se encuentre en todas las ediciones de la traducción «emendada e corregida» impresa por primera vez en Valladolid en 1500 (véase la nota 20), en las cuales se suprimió el prólogo original del autor y se sustituyó por una Introducción puesta a su nombre totalmente apócrifa. Transcripción revisada por M. ${ }^{a}$ Dolores González-Ripoll (Centro de Estudios Históricos, CSIC) sobre el ejemplar de la edición de 1511 conservado en la Biblioteca de Palacio (Madrid).

28 La edición de 1515 se inicia con esta portada: «Tractat fet per lo Magnífich mossèn Manuel Dieç e dirigit a l'Excel-lent e Reverendíssim senyor Don Alfonso de Aragó, Archebisbe de Saragoça et cetera...» Y el citado Prohemi, que viene a continuación, dice así: «Prohemi dirigit a l'Excel-lent e Reverendíssim senyor Don Alfonso de Aragó, Archebisbe de Saragoça, et cetera. - Excel-lent e Reverendíssim Senyor.- Veent la maolta [sic] necessitat que tenen los cavallers quant són en lo camp seguint les guerres per mantenir la honra y estat de son Rey e senyor, car si per cas los esdevé que lo cavall los manca per naffres ho per qualsevol altres accidents és causa que dits cavallers no poden augmentar la honra de son propi Rey ni lur, e per ço yo, Manuel Dieç, humil vassall de vostra Excel-lent senyoria, he compost lo present libre, compartit en tres bolums: lo primer tractarà de les mules, lo segon dels cavalls, lo terçer de l'anothomia de dits animals, axí com largament porà veure en lo present libre. Supplicant a la Excel-lent senyoria que de mi, humil vassal seu, vulla acceptar aquest petit present, lo qual per rahó se poria anomenar Espill de cavallers. E yo reste supplicant a la divina clemència que augmente lo estat de vostra Reverendíssima persona». Tanto este Prohemi como la alusión de la portada se repiten en la edición de 1523 . Alfonso de Aragón, hijo natural de Fernando el Católico, arzobispo de Zaragoza y de Valencia, humanista, protector de humanistas, interesado por el lulismo, y personaje importante en la primera imprenta zaragozana, era lugarteniente general de la Corona de Aragón en la época de la primera edición catalana y fue regente tras la muerte del rey, hasta la llegada de Carlos I (al tiempo que Cisneros lo era en Castilla). En estas ediciones, los editores intervinieron en el texto hasta el punto de invertir el orden original de los tratados que contiene. Sobre el supuesto tercer tratado, de «anatomía», véase la nota 48.

29 Véase la nota 18. 


\section{LLUÍS CIFUENTES Y CARMEL FERRAGUD}

1515 y 1523, estos últimos (como la traducción castellana) con fabulosas dedicatorias y atribuciones dictadas por los intereses editoriales - por otro lado muy características de la primera imprenta-, confundió a bibliófilos e historiadores ${ }^{30}$. Éstos —que con frecuencia se han limitado a la consulta de los libros impresos en catalán y, sobre todo, en castellano- han repetido acríticamente los datos ofrecidos por los editores del Quinientos, en ocasiones incluyendo alusiones causales a las grandes pérdidas de caballos supuestamente sufridas por el ejército de Alfonso durante la campaña de Nápoles, de la misma procedencia ${ }^{31}$.

Con todo, es posible que la referencia a la conquista de Nápoles no fuera un simple invento de los editores y que conectase con una cierta tradición oral. No sólo la presencia de Manuel Dies en la campaña de Italia de 1420-1423 está perfectamente documentada, sino que las alusiones a la guerra y a las conquistas, a la necesidad por parte de los caballeros jóvenes de conocer el arte de la albeitería en tiempo de guerra, cuando no siempre tienen a mano a algún albéitar, son ciertamente frecuentes en la obra. Fue, posiblemente, en Nápoles donde encontró una de sus fuentes principales, el tratado de Lorenzo Rusio - quien sabe si en latín o en italiano-, que se llevaría a Valencia. También es posible que Alfonso acogiera la obra con el suficiente entusiasmo como para favorecer su difusión. Pero de aquí a deducir un encargo directo del rey, o una supuesta conferencia de albéitares para documentarse, va un camino muy largo que, sin más documentación de la que disponemos, no podemos recorrer. Por otra parte, esta supuesta conferencia de albéitares contradice de lleno la influencia de las dos fuentes principales de la obra, antes descrita. En cuanto al encargo real, no hay duda de que Alfonso fue un príncipe «ab amor de la scièntia» y de los libros, como elogiaron ya sus contemporáneos, ${ }^{32}$ pero no podemos saber si influyó en un

30 Véase, por ejemplo, Ribelles Comín, J. (1915), vol. 1, pp. 142-43; SANZ EGAÑA, C. (1941), pp. 101 y 103; FARAudo De SAINT-Germain, Ll. (1949), p. 26; o Dualde PÉreZ, V. (1997), p. 260. El Prohemi de las ediciones catalanas motivó que algunos decidieran que el autor de la obra no podía ser el mayordomo del Magnánimo, a quien bautizaron como Manuel Dies «lo antich», sino que debía ser su hijo homónimo, a quien llamaron Manuel Dies «lo modern» (véase BALDAQUí y BALDAQUí [1993], p. 265).

31 «Los grandes obstáculos que D. Alfonso de Aragón tuvo que vencer antes de rendir las provincias del Abruzo, y las hostilidades de una guerra cruel, dio lugar a que enfermara su numerosa caballería de cierto género de epizootia, de la que morían sin asistencia los caballos por falta de albéitares. Esta mortandad de caballos que se notó y la carencia de profesores que pudiesen remediar el mal, indujo indudablemente al rey a tomar la determinación que tomó, mandando a su mayordomo mayor Manuel Díaz, que reuniese a todos los mariscales de su real caballeriza y ejército, para que de común acuerdo celebrasen conferencias bajo la presidencia de Díaz, y éste formase un libro de Albeitería: Díaz cumplió el mandato del rey y escribió su libro en lengua catalana...» (MORCILLO OLALLA, J. [1883], pp. 53-54).

32 Véase el bello elogio de ANTONIO BECCADELLI, el Panormita: «Ab amor de la scièntia.-Quant lo rey prenia e dava a sacomano una ciutat o terra, qualsevol cavaller o soldat qui prenia libre algú o trobava, se tenia per dit de trametre'l o dar-lo a la Sua Alteza, per quant tots sabien, y tal era la fama, que li'n feyen singular servey, he ab res no podien tant guanyar-li la voluntat com fent-li present de algun 


\section{EL «LIBRE DE LA MENESCALIA» DE MANUEL DIES}

Manuel Dies posiblemente interesado ya por la materia. Hay que señalar, contra lo que se ha supuesto en alguna ocasión, que el ejemplar manuscrito de la biblioteca real de Nápoles (hoy en París) jamás estuvo en manos de Alfonso: únicamente prueba, nada más y nada menos, la gran difusión y aceptación de la obra entre un público primordialmente nobiliario ${ }^{33}$.

\section{LA NOBLEZA Y EL ARTE DE LA ALBEITERÍA}

Los primeros destinatarios que el propio Manuel Dies había previsto para su obra eran los caballeros. Efectivamente, si declaró haber escrito el Libre de cavalls «per mostrar als jòvens cavallers e gentils hòmens, los quals per poqua edat no.n saben [...] gran part de la pràtiqua e de la conexença dels cavals e de llurs malalties, e gran part de les cures de aquells $»^{34}$, el Tractat de les mules afirmó haberlo elaborado expresamente para los «cavallers vells, qui en lur jovent han seguit lo mester de les armes [e] lurs persones ne romanen cascades axí per los grans trebals com per les nafres que rebudes hauran e quant se lexen de portar armes per lur vellessa cové que per anar mils reposats cavalquen mules» ${ }^{35}$.

Como bellamente se expone en el prólogo de la obra, durante la época medieval el caballo era, fundamentalmente, un animal para la guerra. $\mathrm{Y}$ en los ejércitos bajomedievales, a pesar del peso creciente de los mercenarios a sueldo, la caballería continuaba siendo cosa de la nobleza feudal. El caballo posibilitaba hacer la guerra en condiciones al caballero, pero también le otorgaba un estatus social superior ${ }^{36}$. Es por

digne libre» (Dels fets e dits del gran rey Alfons, lib. 2, cap. 14 [=15], traducción catalana del s. XV del caballẹro valenciano Jordi de Centelles, ed. por DURAN, E. [Barcelona, 1990], p. 145).

33 París, Bibliothèque Nationale, ms. Esp. 215, s. XV, procedente de los bienes confiscados a Pedro de Guevara, marqués de Vasto y gran senescal del reino, a raíz de su participación en la Conjura de los Barones (1485-1486), y a cuya mano quizás corresponda la «Reçeta para mal de la nube del ojo del cavallo de maestre Cola, ferrero de Capua», en castellano, añadida en el f. 135v. Véase MOREL-FATIO, A. (1892), Catalogue des manuscrits espagnols et des manuscrits portugais, París, p. 34, § 97; BOHIGAS i BALAGUER, P. (1985), Sobre manuscrits $i$ biblioteques, Barcelona, pp. 105-06; MARINIS, T. de, La biblioteca napoletana dei re d'Aragona, vol. 3 (Milán, 1953), p. 196, y vol. 4 (Milán, 1953), pl. 136; y AVRIL, F., et al. (1982), Manuscrits enluminés de la péninsule Ibérique, París, p. 125, núm. 140, y pl. LXXVI.

Parece originario de los mismos círculos el ejemplar visto por Nicolás ANTONIO en la biblioteca del papa Alejandro VII (1655-1667), con una especie de recetario añadido al final escrito en un castellano muy catalanizado y dirigido a un anónimo personaje sin práctica en el arte de la albeitería: «Por tal que vos no havéis, segunt creo, mucha práctica del art de menascallía...» (véase la nota 18).

34 MANUEL DIES, Libre de la menescalia, lib. I, prólogo. Véase el Apéndice III.

35 MANUEL DIES, Libre de la menescalia, lib. II, prólogo. Véase el Apéndice IV.

36 MANUEL DIES, Libre de la menescalia, lib. I, prólogo, transcrito en el Apéndice III. Véase, por ejemplo, BACHRACH, B. S. (1985), «Animals and warfare in early medieval Europe», en L'uomo di fronte al mondo animale nell'Alto Medioevo, Spoleto [=Settimane di Studio sull'Alto Medioevo, XXXI], 


\section{LLUÍS CIFUENTES Y CARMEL FERRAGUD}

esta razón que, tal como indicó Ramon Llull a finales del siglo XIII, para un buen caballero, tan importante es mantener preparado su arnés como saber «menescalcir» a su caballo ${ }^{37}$. Llull no cita a los albéitares, pero - como la de la medicina académica y los propios médicos graduados- la presencia y la valoración social de éstos y de la práctica de su oficio con las garantías que ofrecía el arte de la albeitería, con idénticos presupuestos doctrinales que la medicina humana (elementos, humores, complexiones, etc.), serán crecientes a lo largo de la Baja Edad Mediaa ${ }^{38}$. Esto no debía excluir que saber «menescalcir» continuara siendo considerado por la nobleza como consustancial a la caballería, también por pragmatismo, «car en les guerres no van totstemps ab lo menescal de prop» ${ }^{39}$ : Una investigación reciente sobre la asistencia sanitaria en los ejércitos medievales de la Corona de Aragón nos ha confirmado que, si bien éstos contaban con albéitares, a menudo su número no debía ser suficiente ${ }^{40}, \mathrm{y}$ resultaba necesario, pues, que los nobles tuvieran nociones de albeitería. A parte del propio Manuel Dies, el médico Jaume Roig, en su Espill (ca. 1455-1462), nos proporciona otro magnífico testimonio al respecto ${ }^{41}$. La documentación conservada nos

vol. 1, pp. 707-51, en particular la p. 749; CONTAMINE, P. (1972), Guerre, état et société à la fin du Moyen Âge: Études sur les armées des rois de France, 1337-1494, París-La Haya, pp. 13 y ss., 171 y ss., 301 y ss., 367 y ss., passim; y AYTON, A. (1994), Knights and warhorses: Military service and the English aristocracy under Edward III, Woodbridge.

37 «Tenir jent son arnès e manascalsir son cavayl és offici de cavayler» (RAMON LLULL, Llibre de l'orde de cavalleria, ed. de SOLER i LLOPART, A. [Barcelona, 1988], p. 185, datado hacia 1274-1276). Disposiciones similares se podían encontrar en Castilla durante la misma época; las Partidas de Alfonso el Sabio (1252-1284) obligaban a todos los caballeros a «ser sabidores, para conservar los caballos», en estas tres cuestiones: «La primera, saberlos mantenerlos en sus bondades; la segunda, si alguna mala costumbre oviesen, tollerlos della; la tercera, guarescerlos de las enfermedades que oviesen» (Las Siete Partidas del Rey Don Alfonso el Sabio, ed. de la RAH [Madrid, 1807; reimpr.: Madrid, 1972], Partida Segunda, Título XXI, Ley X); véase SANZ EGAÑA, C. (1941), pp. 19, 103 y 193. La Segunda Partida fue traducida completa al catalán (mss. 942 de la Biblioteca de Catalunya y Y-III-4 de El Escorial) en el siglo XIV; Pedro IV (III) incorporó esta traducción, con ligeras modificaciones, en su Tractat de cavalleria, redactado antes de 1387; el texto citado corresponde a la Ley XVII («Com los cavallers deuen saber conèxer los cavalls e les armes si són bons o no») del tratado del rey Pedro. Véase D'ABADAL i de VINYALS, R. (1912-1913), «Les Partides a Catalunya», Estudis Universitaris Catalans, 6, 13-37, 159-80, y 7, 118-62, en las pp. 27-29; BOSCH, S. (1936), «Les Partides i els textos catalans didàctics sobre cavalleria», ibidem, 22 [=Homenatge a Antoni Rubió $i$ Lluch, vol. 3], 655-80; y BOHIGAS i BALAGUER, P. (1947), Tractats de cavalleria, Barcelona, pp. 124-25 y 211. MANUEL DIES (Libre de la menescalia, lib. I, prólogo, transcrito en el Apéndice III) reproduce este fragmento procedente de las Partidas prácticamente en los mismos términos.

38 Véase CifuENTES, FerRagud y GarCia BALLESTER (1998, en prensa).

39 MANUEL DIES, Libre de la menescalia, lib. I, prólogo. Véase el Apéndice III.

40 CIFUENTES, Ll. (1995) Medicina i guerra a l'Europa baix-medieval: La sanitat i la participació dels seus professionals en les expedicions militars de la Corona d'Aragó, 1309-1355, Bellaterra, ed. en microfichas, 1995 (tesis doctoral, Universitat Autònoma de Barcelona, 1993).

41 «A peu aní / en Catalunya, / hon fiu ma punya, / que hun cavaller / <molt $>$ gran bandoler, / d'antich linatje, / me pres per patje. / Ab ell vixquí / fins que n'ixquí / ja home fet. / Ab l'om discret / temps no 
ofrece otros ejemplos igualmente explícitos. Destacaremos tan solo un proceso de finales del siglo XIV contra el albéitar de Valencia Antoni de Vallespinosa, defendido por cuatro de sus clientes habituales, todos ellos caballeros de la ciudad; éstos, además de dar testimonio de la competencia del albéitar, demostraron, en el interrogatorio, un amplio conocimiento de los principios del arte de la albeitería ${ }^{42}$.

En consecuencia, no debe extrañarnos el hecho de que en las bibliotecas nobiliarias bajomedievales nunca faltaran los libros de albeitería, preferentemente en lengua vulgar. Fruto de un interés social creciente por las quaestiones naturales, al lado de estos libros figuraban a menudo los manuales que garantizaban la crianza y la sanidad de otros animales, como los halcones o los perros, que, con los propios caballos, eran utilizados en la distracción predilecta de la nobleza: la caza. La lengua vulgar fue el puente preferido por estos grupos sociales, constituidos, en el caso de la albeitería, sobre todo por la nobleza pero también por la burguesía emergente, para acceder a los conocimientos sanitarios que eran considerados con más garantías: las que ofrecía el arte de la albeitería ${ }^{43}$. Lo podemos verificar fácilmente si hacemos un análisis de los inventarios de las bibliotecas de nobles y burgueses que se han conservado (en los cuales el tratado de Manuel Dies tuvo pronto una presencia muy destacada) y de las anotaciones y características de los manuscritos que han llegado hasta nosotros ${ }^{44}$.

Pero contrariamente a lo que se ha dicho a menudo, basándose únicamente en el testimonio de los autores en sus prólogos, no fueron tan solo los nobles y burgueses los destinatarios de estos escritos de albeitería. Aunque es más difícil de documentar, también los prácticos en la albeitería estaban familiarizados con esta literatura, la

\footnotetext{
y perdí: / d'ell aprenguí / de ben servir, / armes seguir; / fuy caçador, / cavalcador / dels bons dels regnes: / bona mà en regnes, / peu i sperons; / de tots falcons / hi d'esparver, / ginet, cosser, / de cetreria, / menescalia, / sonar, ballar: / fins a tallar / ell me'n mostrà!» (JAUME ROIG, Espill, vv. 968-995, ed. en 2 vols. de MiQuel i PlANAS, R. [Barcelona, 1929 y 1950], vol. 1, pp. 18-19).

42 ARV, Justícia Civil (Peticions), reg. 3682, del año 1367. Tenemos prevista la edición de este interesante proceso.

43 CIFUENTES, Ll. (1997), «'Translatar sciència en romans catalanesch': La difusió de la medicina en català durant la Baixa Edat Mitjana i el Renaixement», Llengua \& Literatura, 8, 7-42.

44 CIFUENTES, Ll. (en preparación), La medicina en català. Copias cuidadosas, escritas con diversas tintas, con iniciales ricamente ornamentadas, en ocasiones sobre pergamino y a dos columnas, caras, en definitiva, apuntan hacia propietarios de un sólido potencial económico. Señales o anotaciones indicando o repitiendo partes del contenido - en especial los títulos de los diferentes apartados- nos descubren un tipo de lector no profesional; por contra, las anotaciones que un lector del oficio solía hacer tendían a comentar o ampliar el contenido del texto. Véase el análisis que se efectúa en CIFUENTES, Ll: (1999), "Vernacularization as an intellectual and social bridge: The Catalan translations of Teodorico's «Chirurgia» and of Arnau de Vilanova's «Regimen sanitatis»», Early Science and Medicine, 4 [=The vernacularization of science, medicine and technology in late medieval Europe, III, ed. por CROSSGROVE, W.; SCHLEISSNER, M. y VOIGTS, L. E.], pp. 127-48
} 


\section{LLUÍS CIFUENTES Y CARMEL FERRAGUD}

poseyeron y fueron sus divulgadores ${ }^{45}$. De hecho, los albéitares y los propietarios de caballos en general utilizaron siempre la terminología técnica propia de los tratados, y actuaron sobre las bestias siguiendo escrupulosamente las indicaciones terapéuticas adecuadas según estos escritos ${ }^{46}$. Por otro lado, algunos albéitares fueron autores de adaptaciones o de extractos del contenido de estos tratados. A parte de algunos extractos anónimos, sabemos que el tratado de Manuel Dies fue objeto de una adaptación hecha, hacia mediados del siglo XV, por el albéitar Salvador Vila, probablemente de Barcelona ${ }^{47}$. Cuando los exámenes sean preceptivos para los albéitares, las obras de albeitería incorporarán cuestionarios prácticos. Es el caso de la adaptación de Salvador Vila, de las ediciones de la traducción castellana del libro de Manuel Dies a partir de la de 1500, y de las ediciones catalanas basadas en éstas ${ }^{48}$. Entonces,

\footnotetext{
45 Los inventarios de albéitares son muy escasos. Antoni Martí, albéitar de Valencia, poseía, entre otras cosas, «una caxa de pi xiqua en la qual havia set coltells de menescalia; ítem tres mordaces; ítem tres escofines; ítem dues tenalles de ferrarr; ítem un boqual o més; dos martells sense mànchs; ítem cinch anelles de ferre; [...] ítem un libre de menescalia ab cubertes vermelles; ítem altre libre de menescalia ab cubertes verts; ítem un libre de cirurgia ab cubertes blanques...» (ACP, vol. 1357, ff. 51v-52, 24-07-1395).

46 CifUENTES, FERRAGUd y GARCIA BALLESTER (1998, en prensa). Véase el documento citado en la nota 42 .

47 Probablemente constituya un extracto de la obra de Dies (es necesaria una investigación más cuidadosa) el recetario del ms. 1142 de la Bibl. Universitaria de Bolonia, del s. XV, quizás de origen mallorquín y con anotaciones de albéitares italianos de finales del XV o principios del XVI; fue publicado parcialmente por BATLLORI, M. (1932), «Un llibre de manescalia en català a la Biblioteca Universitària de Bolonya», Anuari de l'Oficina Romànica de Lingüística i Literatura, 5, 179-223 [reimpr. en IDEM (1993), Obra completa, Valencia, vol. 1, pp. 217-65]

El texto de Salvador Vila, inédito (ms. 423 de la Biblioteca de Catalunya), es declaradamente una adaptación: «e per so jo, Salvador, menescall, é pres un petit trachtat de aquel cavaler que-s diu mosèn Manuell Dies, senyor d'Endilla e cavalerix del potentísimo senyor Don Anfonso, rey d'Aragó et cetera, e per mi exeminats en lo tems que he viscut, lo qual ordonaré per capítols axí com se seg<u>ex...» (f. $38^{\mathrm{a}}$ ); en cambio, el autor presenta como original el capítulo sobre la manera de engordar a las bestias: «e per tant, jo, Salvador Vila, é posat a la fi de mon libre vint-e-sinch maneres de potatges...» (f. $\left.52^{\mathrm{b}}-54 \mathrm{v}^{\mathrm{b}}\right)$. Véase POULLE-DRIEUX, Y. (1966), p. 39.

48 La obra de Salvador Vila acaba con un cuestionario, pretendidamente de anatomía pero, en realidad, «de les coses que pories ésser enterrogat segons acostuman los antichs mestres en exheminar un novisi». La tercera parte del volumen editado en Barcelona en 1515 se inicia con esta rúbrica: «Lo següent tractat és de l'anothomia dels cavalls, ço és, de les interrogacions e respostes que-s deuen fer en lo examen de qualsevol menescal, lo qual tractat és molt necessari e profitós per qualsevol menescal ho ferrer». El cuestionario, más extenso que el de Salvador Vila, empieza así: «Primerament, vos deman quina cosa és menescalia. Respon: menescalia és saber conèixer les malalties dels cavalls e donar recapte e cura en aquelles, e traure sanch del cavall la que és menester segons la qualitat e complecció de aquell...»; algunos breves fragmentos de este cuestionario fueron publicados por BARBERÀ MARTí, $\mathrm{F}$. (1914), p. 34. Las ediciones en castellano incluyen un cuestionario a partir de la de Valladolid de 1500 (Libro de albeytería, emendado et corrigido, et añadidas en él sesenta et nueve preguntas). También hay cuestionarios similares en un ms. del siglo XV que contiene el Libro de fecho de los cavallos en castellano (Madrid, Real Academia de la Historia, ms. 9-444, olim Salazar F 38, ff. 62-92v) y otro del s. XVI que contiene Los siete libros del arte de la ciencia de albeitería de Bernardo Portugués y otras obras
} 


\section{EL «LIBRE DE LA MENESCALIA» DE MANUEL DIES}

ninguno de los editores, en castellano o en catalán, olvidará dejar muy matizada la alusión única de Manuel Dies a los caballeros ${ }^{49}$.

\section{LOS LIBROS DE ALBEITERÍA Y LOS ALBÉITARES}

Fuera de los usos más vinculados a la nobleza, como la guerra y la caza, algunos équidos, sobre todo los menos valiosos y más resistentes (rocines, mulas y asnos), resultaban indispensables para el trabajo de la tierra y para el transporte. Como en el caso de los caballos, los halcones o los perros de los nobles, las razones económicas fueron importantes para que se tomara conciencia de la necesidad del mantenimiento de estos animales de labor, también en los aspectos sanitarios.

A menudo eran los herreros los que asistían a estas bestias, algunos de los cuales se dedicaron preferentemente a la albeitería y por eso fueron conocidos como «ferrers e menescals» (herreros y albéitares). De esta forma, a pesar de que los reyes y los nobles tenían albéitares a su servicio, en los cabreos, fogajes y ordenanzas de los «mostassafs» (almotacenes) de las ciudades no faltan los «ferrers e menescals» al lado de los mismos albéitares. Juntos formaron cofradía (en Valencia, desde 1298) y gremio, y juntos accedieron a los consejos municipales ${ }^{50}$.

Al menos en el marco de la Corona de Aragón, al cual se refiere primordialmente este trabajo, parece que los albéitares musulmanes tuvieron un peso importante, sobre todo en el reino de Valencia (pero también en Aragón), donde la ruralización de la comunidad sarracena y la emigración de sus élites después de la conquista limitó considerablemente la expansión de su medicina y la de sus prácticos, forzosamente

(Madrid, Biblioteca Nacional, ms. 3338, ff. 100-128v). Véanse los comentarios, no siempre acertados, de SANZ EgAÑA, C. (1941), p. 103; Poulle-DrieuX, Y. (1966), p. 117; y Dualde PÉREZ, V. (1997), p. 266. Por ser cronológicamente más próximo a la elaboración de la obra de Manuel Dies, reproducimos en el Apéndice VII el cuestionario de Salvador Vila.

49 Las ediciones en catalán de 1515 y 1523 especifican en la portada que el tratado «és profitós e molt necessari per qualsevol cavaller o gentilhome ho per qualsevol altra persona que té cavall ho mula ho qualsevol altre animal de cella, ço és, per conèixer los bons e mals senyals de dits animals e per conèixer totes les malalties e saber curar aquelles, e axí mateix és molt necessari lo present tractat per qualsevol ferrer ho menescal». En la Introducción añadida a las ediciones en castellano (véase la nota 20) a partir de la de 1500 se advierte que con: «[...] este libro de albeytería [...] cada uno de súbito puede curar de algún accidente que a su cavallo, mula o otra bestia sobreviniere no hallando albéitar; mas hallándolo que sea bueno, deve dexar la cura al maestro que es más sufficiente por la prática que no él». Pero la portada de la edición de 1545 ya invierte los términos: «Libro de albeytería muy útil y provechoso no solamente a los albéitares más aún a todas y qualesquier personas que tienen y crían cavallos o mulas...»

50 Cifuentes, FerRAgud y GARCIA BALLESTER (1998, en prensa). 


\section{LLUÍS CIFUENTES Y CARMEL FERRAGUD}

marginados - como la propia albeitería - de la nueva institución universitaria ${ }^{51}$. De hecho, los albéitares musulmanes fueron especialmente preciados, incluso en la corte, a cuya sombra progresaron importantes linajes, como por ejemplo el de los Bellvís aragoneses o el de los Abenxoha valencianos ${ }^{52}$.

Sin embargo, la fama de los albéitares musulmanes no debe hacernos perder de vista que el contexto era cristiano: lo eran la mayoría de los albéitares (y de los herreros-albéitares), lo eran los textos del arte de la albeitería, en la cual se cimentaba la práctica que era considerada cada vez más como la más adecuada, y lo fue la progresiva reglamentación del oficio. En la Corona de Aragón, un siglo después de la creación de un marco legal para la práctica de la medicina ${ }^{53}$, se aplicó un modelo muy semejante a la albeitería: exigencia de un examen y formación de tribunales examinadores municipales (1436), que a pesar del intervencionismo de la monarquía facilitado por el enfrentamiento entre herreros y albéitares (1479), acabarían siendo regulados y controlados por el mismo gremio, ya reconciliado, con el decidido apoyo del municipio $(1483)^{54}$. A pesar de los intentos de control por parte de la monarquía, con el nombramiento de examinadores mayores (desde 1450), la regulación de los exámenes (1479) o la creación de tribunales examinadores centralizados (1500), la fuerza de los gremios determinó que éste fuera el sistema vigente en la Corona de Aragón hasta la Nueva Planta que, como en otros ámbitos, significó la imposición de las instituciones castellanas, en este caso del Real Tribunal del Protoalbeiterato ${ }^{55}$. Probablemente, fue esta evolución en la reglamentación del oficio, más allá del afán

51 GARCIA BALLESTER, L. (1976), Historia social de la medicina en la España de los siglos XIII al XVI, Madrid, vol. 1 (La medicina musulmana y morisca), pp. 29-57; e IDEM (1988), La medicina a la València medieval: Medicina $i$ societat en un país medieval mediterrani, pp. 31 y ss.

52 Cifuentes, FERRAGUd y GARCIA BALLESTER (1998, en prensa).

53 Véase fundamentalmente GARCIA BALleSTER, L., MCVAugh, M. R., y Rubio Vela, A. (1989 [=1990]), Medical licensing and learning in fourteenth-century Valencia, Filadelfia (Transactions of the American Philosophical Society, núm. 79/6); y MCVAUGH, M. R. (1993), Medicine before the plague: Practitioners and their patients in the Crown of Aragon, 1285-1345, Cambridge.

54 DUALDE PÉREZ, V. (en prensa), «Los exámenes de albeitería («menescalia») en el Reino de Valencia durante el siglo XV», I Col-loqui internacional «Civitas Europa»: Art, cultura i societat al segle XV (València, 4-9 nov. 1996), reproducido en IDEM (1997), pp. 62, 160, 162-63 (con facsímil del documento de 1479), 393 y ss., § 4, 423-25 (transcripción del documento de 1483) y § 11, 434-36 (transcripción del documento de 1479). A partir de los capítulos de 1483, el gremio elegía a los dos mayorales examinadores y admitía en el tribunal a los dos médicos examinadores de médicos de la ciudad. A pesar de que las ordenanzas limitaban el marco geográfico de la normativa a la ciudad y su término, en las licencias nunca se olvidaba hacer constar su validez para todo el reino (ibidem, pp. 160 y 177). Véase la nota 56.

55 Este hecho, obviado por SANZ EGAÑA, ha sido recientemente destacado por DUALDE PÉREZ, V. (1997), pp. 158, 160 y ss., 181 y ss. y, en particular, 449. Véase la licencia «de usar e pratiquar liberament de la dicha menescalería por toda la tierra e senyoría del dito senyor rey», otorgada (1468) por Gonçalvo de Cáceres, «prohomenescal del senyor rey» desde 1459, a Juan Daudans, albéitar de Huesca, tras haberlo examinado, publicada per SERRANO SANZ, M. (1916), «Menescal = veterinario, menescalería = veterinaria», Boletín de la Real Academia Española, 3, 93. 


\section{EL «LIBRE DE LA MENESCALIA» DE MANUEL DIES}

de lucro, la que indujo a los editores del siglo XVI a justificar cuidadosamente y sin escrúpulos el hecho de que un individuo que era ajeno a la práctica, y además noble, fuera autor de un libro de albeitería, y a buscar el mercado de los albéitares y no únicamente el de los nobles.

Los importantes documentos de 1436 , recientemente descubiertos ${ }^{56}$, se inscriben en el esquema que hemos expuesto, a la vez que descubren la auténtica valía de la obra de Manuel Dies y el compromiso personal, intelectual y de reforma social de éste con el arte de la albeitería. Las autoridades municipales de Valencia exigieron a partir de aquel año, apelando al provecho de la cosa pública, un examen previo para todos los que quisieran practicar la albeitería en la ciudad y su reino. Para hacerlo efectivo, se nombró una comisión con la finalidad de escoger dos albéitares aptos en calidad de «majorals e examinadors de menescals» en los años siguientes. Esta comisión de selección la formaron el lugarteniente del justicia civil de Valencia, tres de los jurados de la ciudad, un cirujano, dos maestros en medicina y dos caballeros. Uno de los médicos fue Jaume Roig, el autor del Espill, examinador de médicos en Valencia, médico de la reina María y consejero de la ciudad. Uno de los caballeros no fue otro que el propio Manuel Dies. La presencia de los médicos nos confirma la estrecha vinculación entre la medicina humana y la medicina animal. La presencia de los caballeros, y en concreto la de Manuel Dies, nos evidencia su interés por una materia en la cual este último ya era altamente respetado, por la fama que le debía haber proporcionado su Libre de la menescalia.

Como ocurrió con la medicina humana, el nuevo reino de Valencia, patria de Dies y con la principal urbe de la Corona de Aragón en el siglo XV, parece que también estuvo a la vanguardia en la institucionalización de la práctica de la albeitería. Un proceso de institucionalización que implicó a todos los grupos sociales dominantes, con importantes conexiones con el que había afectado a la medicina, y que proporcionó un nuevo público a los tratados de albéitaría: el de los propios albéitares. Siguiendo el ejemplo de los prácticos en la cirugía, los albéitares se dotaron de intrumentos intelectuales y técnicos adecuados (guías) con los que poder enfrentar con éxito dicho proceso. A la hora de seleccionar o componer esos instrumentos, tuvo un papel muy destacado la última albeitería italiana, importada a Valencia y al resto de la Corona de Aragón, y más tarde difundida a Castilla y a Francia, gracias a la obra de quien fue mayordomo del Magnánimo.

56 DUALDE PÉREZ, V. (1985), «Notas sobre Albeytería en el reino de Valencia: Exámenes de albéytares en el siglo XV», Boletín de la Sociedad Castellonense de Cultura, 61, 393-97; IDEM (en prensa), «Los exámenes»; e IDEM (1997), pp. 158-61 (con facsímiles de los documentos), 260, 393 y 405, y § 9 y 10, pp. 433-34 (transcripciones). Por su importancia, los hemos reproducido también, con una transcripción revisada, al final de este trabajo (Apéndices V y VI). 


\section{LLUÍS CIFUENTES Y CARMEL FERRAGUD}

\section{APÉNDICES}

1344, octubre 18. Barcelona.

Capítulo relativo a los mayordomos de las Ordinacions de la cort dictadas por Pedro III (IV) el Ceremonioso, plenamente vigentes en la Corona de Aragón durante el siglo XV.

ACA, C, reg. $1529,2^{\mathrm{a}}$ parte 1 .

Publicado por BOFARULL i MASCARÓ, en la CODOIN, vol. 5, pp. 11-182.

\section{DELS MAJORDÒMENS}

Utilitat e ornament de nostra cort real concernens, havem cogitat molt ésser necessari que alscunes coses que per lo offici de majordom çaentràs degudament, sens constitucion real, estants, per adjutori de nostra auctoritat sien aprovades e aquelles altres coses no degudament observades sien corregides per remey de nostra Serenitat, ab savi consell introduiit. D'on, ab aquest edicte, decernim observador que en la nostra cort tres nobles cavallers - la un en lo regne d'Aragó, l'altre en los regnes de València e de Mallorcha e l'altre en Cathalunya- e dos altres simples cavallers, d'offici del majordom sien ennobleïts, e entres aquests emperò evidenment se pertanyen los nobles cavallers, cor, con alscunes coses qui-s pertanyen a l'offici d'aquests faedores sien de magnificència e mayors, pus alt estament requeren d'aquell qui exercexs l'offici. De necessitat, encara, és dos ésser cavallers decorats de l'offici dessús dit, cor con sovén per moltes coses esdevenir se pusqua un d'ells, al qual contínuament necessitat de servir és imposada, per necessitat o per qualque altra manera, ésser absent, per lo present e romanent los serveys se pusquen complir ne l'absent no haja a altre cometra ses veus, cor con altres coses ne aytals no·s degen per altre fer ne espatxar sinó per hu d'aquests, los quals per singular indústria, examinada la fe d'ells e la granea a la magnitut d'aquest offici, prenem. Los damunt ditz, emperò, cavallers, al noble majordom de la terra on Nós serem, mentre Nós hi serem —ço és, que si som en lo regne de Aragon, al majordom noble d'aquell regne, e per semblant manera, si som en Cathalunya al noble majordom de Cathalunya, e si som en lo regne de València o de Mallorcha a cascun dels nobles majordòmens estants-nos en la majordomia de cascun- obeyran en totes aquelles coses qui s'esguarden en lurs officis e axí con a majors hauran.

E a l'offici d'aquests són imposats los serveys qui-s seguexen, cor lo majordom servén, segons la nostra volentat, la qual cascun dia sia tengut de saber, quines viandes volrem menjar e aquelles man apparellar. E sia curós ab acabament que les viandes e altres coses en nostre

1 Copia de 1787, en cuya fecha el ejemplar del Archivo de Barcelona fue enviado a Madrid por real orden de 20 de noviembre y se perdió. Para los mss. conservados, véase SCHENA, Le leggi palatine, pp. 38-67.

2 Hemos añadido puntuación y acentuación modernas. 


\section{EL «LIBRE DE LA MENESCALIA» DE MANUEL DIES}

palau aministradores sien a hora deguda apareylades. Faça encara, Nós manans, en nostre palau taules e altres coses aquí necessàries fer e, con serem prop d'anar a taula, no tart de pendre nostre manament per lo qual sia imposat quals persones ne per quin orde en nostra taula farà seer davant e aprés Nós. E·ncara, anants per rahó de menjar en palau e d'aquí tornan sia tengut d'anar, e vaja ab hun porter a la cuyna e ab lo sobrecoch exercent l'offici, e, per tal que tota perversa occasió de mesclar coses nocives en nostres viandes a qualquequal malvada persona sia tolta, ab molt gran dil-ligència, per los damunt dits, no tan solament per esguardament de feeltat aprovada los perils de nostra vida esquivans, encara de la vida pròpia perils esdevenir no poch esguardants, e per tal que si la desús dita mescla se fahia, per qualque màcula de legea de tan gran crim se pogués demostrar ans que les dites viandes a la nostra presència pervenguessen, volem e manam que lo dit majordom, davant totes coses, en la cuyna al sobrecoch e als portants lo taylador e als cochs, de totes les viandes que a Nós seran aportades, diligentment tastar faça, e d'aquí avant aquell mateix majordom d'aquelles matexes viandes faça tast - e.l dit majordom, tornan de la cuyna, seguesca los sobrecochs e los portants los tayladors, als quals lo dit porter davant vaja. E.l dit majordom escudelles e talladors sia tengut de posar en nostra taula, e aprés, faça lo tast de les viandes e don-ne a tastar a aquell o a aquells qui les ditas escudellas e talladors hauran portats. E aquestes coses per ell volem que sien fetes en cascuna vianda la qual en un menjar aportadora o posadora serà davant Nós. E volem encara que al nostre boteller, panicer e reboster, del vin e del pan e de fruytes e de les altres coses que per sos officis davant la nostra taula hauran aportades per rahon d'aministrar a Nós d'aqueles, ans que a Nós en la taula o en altre manera ne sien aministrades, aja cura de donar tast e ell mateix pendre $<$ ' $n>$. E de les aygües de les mans a donar a Nós ans que sigam a taula, sie tengut, e d'aquella pendre e donar tast a aquell qui la portarà. $\mathrm{E}$ axí mateix, ans que.ns levem de taula, haja encara, mentre que Nós menjarem, a anar per lo palau e provehir que haja bastament de viandes e d'altres coses segons que-s pertany a real Magestat, e que orde degut en totes coses en lo palau sia observat e, si defalliment hi veurà en alcuna manera, los deffalliments corregesca, degudes maneres observades. E.1 demunt dit majordom, emperò, mentre servirà, port verga congruent en senyal de mostrar auctoritat de manar exercici de servir. E encara per ell sia a Nós ministrat lo pan e les fruytes e les altres viandes, les quals no pertanguen a l'offici de l'apothecari. On si en alcuna manera s'esdevendrà Nós menjar oltra la taula, los serveys desús dits per los camarlenchs disposam de fer.

Ordonam que en les festes de la Nativitat de nostre Senyor, de Pascha e de Pantegosta, e encara quantquequant solemne convit farem, servesca lo majordom noble cavaller del regne on serem, los altres majordòmens a ell acompanyants, per tal que la solemnitat de aytals dies convinentment sia decorada. Si, emperò, s'esdevendrà algunes vegades, en los dits dies, lo noble majordom ésser absent o ésser present empedit per alcun accident, lavors servesque aquell majordom qui primer en lo dit offici serà appellat, l'altre cavaller majordom a ell acompanyant. En los quals dies, als damunt dits sobrecochs e los portants lo taylador de la cuyna, segons que dit és, ab les viandes tornants, dos porters vagen davant ells; en los altres, emperò, dies, contínuament sia tengut de servir un dels dits dos cavallers, ço és, aquell qui primerament haurà pres l'offici desús dit, lo qual absent o present empatxat de servir per algun accident, haja a servir l'altre cavaller, lo qual orde entre los dits cavallers per açò observam: cor, de veus pars e dignitats, per consideració tan solament de temps, devant anar. Si, emperò, en los ditz altres dies no solemnes vol servir lo dit noble, açò pusque fer quantquequant a ell plaurà e a ell haja a fer loch aquell dels dits cavallers al qual segons les coses damunt dites convendrà en altra manera servir, e no-s pens aquell cavaller de sa honor alguna cosa ésser detreta, con lo grau jusà lo mèrit del sobiran regonèxer sia tengut. Si, emperò, los dits dos 
cavallers esdevenien ésser absens o presens empaxats de servir, quantquequant al dit noble majordom present e no empaxat, e encara en los dits altres dies no solemnes, necessitat de servir ab aquest edicte imposam. E encara volem que, quant en lo palau les mans dels pobres, en la taula estants, lavarem, instruïts per divinals fets e doctrines, l'aygua e les altres coses en açò necessàries a Nós degen ésser aministrades per los majordòmens.

Prerogativa d'onor al noble majordom e, aprés ell, a aquell cavaller qui primer serà reebut a l'offici desús dit, segons que·s pertany, sia observada. En aprés, per tal que lo grau jusà totstemps, segons que-s cové, lo mèrit regonega de son sobiran, als dits majordòmens, segons lo grau atribuiit a cascun, en tots aquells qui alcun offici han concernén lo nostre palau donam poder, ço és, en los copers, boteylers, panicers, escuders qui tallen davant Nós, sobrecochs e los portants lo taylador, comprador, cavallerices, sobreazembler e falconer major, los quals tots, si en lur offici hauran fallit, poran de lur quitacion privar per un mes o menys, segons la manera de lur negligència. $E$ en aprés, manam que a aquells qui de nostra Casa seran per lo majordom qui servirà sien dades licències de partir, cor ell la qualitat e la quantitat dels serveys, ab diligència cogitan, porà covinentment arbitrar a quals les dites licències sien otorgadores. Mas l'altre majordom, no servén, licències no pusque donar en neguna manera, sinó lo noble majordom qui, no servén, les damunt dites licències pusque donar, appellat, emperò, l'altre qui servirà per tal que per son consell sàpia si són molt necessaris en los serveys de la cort aquells qui les damunt dites licències demanaran. No volem, emperò, que als sotsmeses al regiment dels camarlenchs e dels algutsirs, e-ncara del canceller e del maestre racional, per algun majordom sia donada licència de partir, ne a negun qui de nostre Consell o d'offici dels escrivans, nostres secretaris, sia ennobleït, cor a nostra Magestat aytal licència de consellers e dels escrivans damunt dits degudament retenim. En aprés, per los dits majordòmens licències sien donades de trer pan e vin e carns e altres viandes de la nostra cort, segons que a ells serà vist rahonable. E con offici de majordom en discutir la rahon de la aministració de nostres officials convinent cosa és, per alguns officials de nostra cort, ço és, lo comprador, boteller, panicer, reboster, sobrazembler e museu, de la aministració lur rahó <sia> retuda e per lo majordom ab lo escrivà de ració aquell sia discutit e hoït, axí que la faeltat dels bons ab laor sia clarificada e la cubdícia desfrenada dels mals sia espaventada. Mas un majordom, almenys una vegada al dia, ab lo dit escrivà de ració cové present ésser en aquest negoci, per tal que la rahó de la aministració, la qual en tantes varietats se posa, per juhy de dos mils sia conservada. En què, en lo dit negoci lo majordom noble sia present, açò cometem a sa volentat, necessitat, emperò, a ell en açò no posam, deferents al seu grau o estament, cor jatsia que aquest negoci s'entena ésser loable, emperò sovinerament és enujós. E encara, tots los majordòmens proveesquen diligentment que per los officials de la boteylaria, de la paniceria, del rebost e de la cuyna, totes coses emposades a lurs officis sien fetes, aquelles coses injunctes a lurs officis, los quals als serveys del palau s'endrecen, e per tal que els dits majordòmens aquesta provesió mils pusquen complir, tenguen translats de les ordinacions disponents les coses concernents lo servey del palau e assignacions dels hostals e del posader que són als officis dels damunt dits imposades. E en aprés, ajustam, cobeejans obviar a perils, que de tots los servidors de la boteyleria e de la paniceria e de la cuyna e del menescal e de la escuderia e del sobrazembler e azemblers e dels falconers, lo noble majordom de la terra on Nós serem o, ell absent o present empaxat, lo majordom cavaller, los serveys, faén homenatge ab sagrament, faelment reebrà, que, aytan com poran e sabran, tots perils que a nostra persona són possíbils esdevenir per aquelles coses les quals per éls exercents lurs officis seran tengudes esquivaran; e-ncara, que els perils pervinents a notícia d'ells en qualque manera a Nós no trigaran de manifestar, o a nostres majordòmens, si a Nós dir no o podien. D'aquestes coses, emperò, ordonades, per 


\section{EL «LIBRE DE LA MENESCALIA» DE MANUEL DIES}

excepció deguda són remoguts aquests officials: botellers majors, panicers majors e sobrecochs e cavallerices e falconer major, qui, per rahó de lurs officis, a Nós, sens migà de fer homenatge, són constrets. En aprés, ajustam que tots los majordoms a Nós homenatge, per adjutori de sagrament roborat faens promèter, sien obligats, que aytant con poran e sabran, esquivaran tots los perils que a nostra persona serien possibles esdevenir, los quals encara perils a la notícia d'éls pervinents en qualque manera a Nós cuytosament manifestaran, e no han fet ne faran alguna cosa per què a les coses desús promeses sens violació observadores puga obviar; e ells, encara, mayordòmens, a Nós, per sagrament tan solament, prometre sien tenguts que ben e faelment l'offici lur exerciran. E con, segons la nostre reyal ordonació dels consellers los mayordòmens conseylers nostres sien enteses, volem que 1 sagrament en la dita ordonació ordonat los desús dits mayordòmens nostres a Nós facen ab acabament ${ }^{3}$.

\section{II}

1418, junio 30. Útebo.

Albarán del escribano de ración dirigido al tesorero del rey para que proceda a pagar la quitación adeudada a Manuel Dies como mayordomo del monarca, oficio en el cual había sido admitido recientemente.

ACA, RP, MR, vol. 837, f. 26.

\section{MANUEL DÍEZ ${ }^{4}$}

A l'honrat En Ramon Fivaller, et cetera ${ }^{5}$. Fas-vos saber que al noble mossèn Manuel Díez, majordom de Casa del senyor Rey, és degut per quitació sua de .VIII. bèsties a les quals és scrit en ració, és a saber, de l'.XI ${ }^{\text {èn }}$. dia del mes de juny proppassat de l'any .M.CCCC.XVII. que.l dit senyor lo manà scriure en carta de ració e.l reebre en lo dit offici, tro per tot lo derrer dia del mes de juny aprés següent de l'any dejús scrit, que són.XI. meses .XX. dies, dels quals tan solament li fas compte de .II. meses.XII. dies que és stat present <en $>$ la cort per absència de .I. dels dos majosdòmens [sic] ordinaris de Casa del dit senyor e de barcelonesos, jatsia partida del dit temps lo dit senyor sia stat en terra de jaquesos, qui a raó de.II. sol. per cascuna

3 «DELS CONSELLERS NOSTRES [...] a tan gran offici de consellers de la nostra Serenitat real sien reebuts canceller e vicecanceller, majordòmens, camarlenchs, maestre racional, tresorer e promovedors, $\mathrm{e}$ encara secretaris qui puguen ésser en aquells, e altres qualsquequals <que> a açò conexerem merexedors [...] En aprés, ordenam que·ls nostres consellers a Nós per sagrament prometre sien tenguts que aytant com poran a Nós bon conseyl e feel daran, dients aquelles coses que sabran conseylladores, favor, odi e temor de tota persona de tot foragitats, e-ncara secret de nostre conseyl servar feelment entendran, e encara que no han feta alcuna cosa, ne faran per avant, que a les coses damunt dites sots sagrament promeses observadores obviar pusquen en qualque manera» (CODOIN, vol. 5, pp. 186-87).

4 Antes se añadió: «noble mossèn».

5 Corresponde a: «tresorer del senyor Rey, de part d'En Gabriel Navarro, scrivà de ració de Casa del dit senyor» (ibid., f. 37). 


\section{LLUÍS CIFUENTES Y CARMEL FERRAGUD}

de les dites bèsties lo dia, per ço com ha tengudes aquelles que per ordinació del dit senyor deu tenir ${ }^{6}$, fan mille centum quinquaginta duo sol. barch. Scrit en lo loch de Húytevo, derrer dia del mes de juny, anno a nativitate Domini $. M^{o} . C C C C^{o} . X V I I I^{o}$.

\section{III}

ca. 1424-1436. La Vall d'Uixó?

Prólogo del Libre de cavalls (lib. I) del Libre de la menescalia de Manuel Dies.

Valencia, Biblioteca Universitària, ms. 631 (mediados s. XV), f. Irv.

Ací comença lo Libre de la menescalia compost per lo noble mossèn Manuel Díez.

En nom sia de la santa Trinitat, qui és Pare e Fill e Sant Sperit, tot un Déu. Com sia molt necessària cosa a tot cavaller e gentilhom e hom d'estat - los quals han a fer les conquestes e les defensions de llurs terres- lo cavall, e com sens aquell exercici d'armes fer no-s pusca per los cavallers e hòmens d'estat, car lo cavaller a peu no pot anar <a> conquerir ne ben defendre sa pròpia pàtria, ans és molt menys en tot treball a peu que los pagesos ne hòmens de tal condició, car són vehats de treballar a peu car lo criament e llur pròpia natura los ho dóna, e lo cavaller e gentilhom lo criament no lo y enclina ne la natura molt menys. E, més avant, que los cavallers an a-anar tots armats de cap tro sus als peus e an a portar armes offensives, e açò per defendre o offendre los enemichs axí com aquells qui són mur e defensió del poble, e, com tan gran càrrech de armes a dur no poguessen a peu, cové necessàriament que vajen a cavall. $\mathrm{E}$ més per fer defferència de cavaller, lo qual si és verdaderament cavaller e tinga lo dret orde de cavalleria per les rahons que antigament foren trobats los cavallers, e axí com ho han exercitat los bons romans e altres cavallers antichs e alguns de nostre temps; e és gran rahó haja tan gran diferència dels cavallers a la gent popular que ells vajen a cavall e los altres a peu. E, per ço, los cavallers antigament, vehent que la pus necessària cosa que havia obs lo cavaller era lo rocí, volgueren e ordenaren que lo dit rocí prengués lo nom del cavaller, ço és, que fos nomenat cavall, car axí com ferre no·s pot obrar sens foch axí fet d'armes no·s pot exercitar sens cavall. Per ço cové necessàriament a tot cavaller e home d'armes saber quatre coses: la primera, saber bé cavalcar; la segona, saber conèxer la bona talla del cavall e les bondats e les aulehes; la terça, saber-lo ben tenir e ben pensar; la quarta, saber conèxer llurs malalties e curar aquelles, car en les guerres no van totstemps ab lo menescal de prop e tal cas pot venir al cavall que si no <é>s ben acorregut se'n perdra, e si lo cavaller pert son cavall en guerra e altre no·n porà haver, pert tota la major part de l'exercici de la cavalleria.

Per què yo, Manuel Díez, majordom del molt alt e poderós príncep e victoriós senyor don Alfonso, rey d'Aragó et cetera, vull fer un Libre de cavalls per mostrar als jòvens cavallers e gentigshòmens [sic], los quals per poqua edat no.n saben, als quals mostraré gran part de la pràtiqua e de la conexença dels cavals e de llurs malalties, e gran part de les cures de aquells.

6 Según se especifica al margen de otro documento referido a él mismo: «Han compte, per ordinació dos, lo noble a .VIII. bèsties e lo cavaller a .VI. bèsties» (ACA, RP, MR, vol. 937, f. 2). 


\section{EL «LIBRE DE LA MENESCALIA» DE MANUEL DIES}

Lo qual libre compartesch en ·XVII capítols: lo primer capítol tractarà de la creació del cavall; lo segon, del dondament del cavall; lo terç, quines ne quantes són les bellehes del cavall; lo quart, de les legehes e aulehes del cavall per tal que mils se'n sàpien guardar; lo cinquè, serà com se deu tenir e pensar cavall jove e com lo cavall que pas de $\cdot V \cdot$ anys en sus; lo sissèn, serà dels pèls, quants són aquells qui per dret no se'n poden nomenar; lo setè, dels afrenaments dels cavalls; lo huytè, quals són los bons senyals e quals los mals; lo novè, quals són los bons remolins e quals los mals per a tot fet d'armes, però no de les blanquehes ne dels remolins, qui no y dóna fe - fa bé, car sobre tot és lo poder de Déu, mas dich-ho per aquells que y paren sment; lo dehè, quals són les malalties naturals e les cures; lo onzè, quals són les malalties accidentals e les cures; lo dotzè, de les sagnies, quantes deuen ésser ne en quin temps per conservar sanitat al cavall; lo tretzè, quant dareu erba, ne en quin temps, ne fins a quant, ne com, e a cavall jove e a cavall vell; lo quatorzè, com tinreu lo cavall en guerra e com en pau; lo quinzè, de les nafres dels cavalls e les cures; lo setzè, com deu ésser ferrat lo cavall.

\section{IV}

ca. 1424-1436. La Vall d'Uixó?

Prólogo del Tractat de les mules (lib. II) del Libre de la menescalia de Manuel Dies.

Valencia, Biblioteca Universitària, ms. 631 (mediados s. XV), f. CI.

Pròlech del següent libre.

Necessari és que parlem de les mules, e açò per tal car los cavallers vells qui en lur jovent han seguit lo mester de les armes lurs persones ne romanen cascades axí per los grans trebals com per les nafres que rebudes hauran e quant se lexen de portar armes per lur vellessa cové que per anar mils reposats cavalquen mules.

E per ço, yo, Manuel Díez, ne faré un petit tractat per lur avisament, lo qual ordonaré en -X. capítols: lo primer, serà de la bellea que mula deu haver; lo segon, dels bons senyals que mula deu haver per ésser bona; lo terç, de les bondats que mula deu haver; lo quart, com la deu fer avear a-amblar; lo cinquè, com la deu tenir; lo sissè, dels pèls; lo setè, de lurs malalties; lo huytè, de les cures; lo novè, com deu ésser ferrada; lo dehè, la conexença si és filla de somera o de egua.

\section{$\mathrm{V}$}

1436, marzo 23. Valencia.

Acta de elección del primer tribunal examinador de albéitares, por una comisión especial nombrada por el Consell municipal de Valencia.

Valencia, Arxiu Històric Municipal, Manuals del Consell, A-31, ff. 73v-74. 


\section{LLUÍS CIFUENTES Y CARMEL FERRAGUD}

Publicado por DUALDE PÉREZ, «Notas sobre Albeytería», pp. 396-97; IDEM, «Los exámenes»; e IDEM, Historia de la albeytería, pp. 433-34, § 97 .

$<$ En el margen izquierdo: $>$ Que neguna persona no usàs de menescalia tro a tant $<$ sia $>$ examinat.

Die veneris, intitulata vicesimatercia mensis marcii, anno a nativitate Domini millesimo quadringentesimo tricesimo sexto, foren justats en la Sala de la Ciutat de València, ço és, en la cambra vulgarment appellada de Consell Secret, los honorables lochtinent de justícia civil, jurats e prohòmens següents:

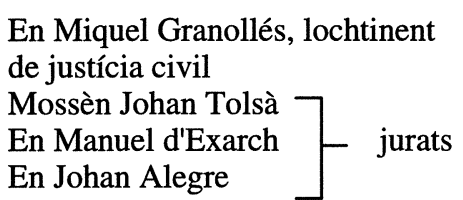

\author{
Mossèn Manuel Díez \\ Mossèn Johan Roiz d'Emorós \\ Mestre Jacme Rotg $\neg$ mestres en \\ Mestre Miquel Climent $\quad$ medicina \\ En Johan Ferragut, cirúrgich
}

Estants tots los damunt dits justats en la dita cambra de Consell Secret, volents entendre en lo benefici de la cosa pública e obviar molts dans que havien moltes bèsties per culpa de mals menescals, hoc en morien algunes per no entendre, conèxer ne saber les malalties de aquelles, fon proveï, ordenat e concordat que de continent, de manament e ordenament dels dits honorables lochtinent de justícia civil e jurats, per En Domingo Valera, verguer de aquells, fossen convocats e manats a si venir a la dita Sala los menescals de la dita ciutat següents:

\section{En Jacme Guerau \\ Mestre Johan de Prades \\ Mestre Miquel Sellés \\ En Domingo Pi}

\author{
Mestre Johan, del rey de Navarra \\ En Lorenç Ballester \\ En March Palàcio \\ En Johan de Salamanca
}

E essents aquí tots los dits menescals justats en la dita Sala, los dits honorables lochtinent de justícia civil, jurats e altres faheren entrar de hun en hun los dits menescals en la dita cambra de Consell Secret e examinaren cascun de aquells diligentment e, fet examen de cascun de aquells, los faheren depuiys entrar tots justats e, stants axí tots justats, los dits honorables lochtinent de justícia civil e jurats, a consell dels damunt dits qui ab ells eren, haüdes diverses col-loquis e parlaments, provehïren de offici de majorals e examinadors de menescals los dits En Jacme Guerau e mestre Johan de Prades, presents e acceptants, e açò a beneplàcit dels dits honorables jurats. En axí que los dits mestre Johan de Prades e En Jacme Guerau fossen tenguts de examinar e entrevenir en lo examen de qualsevol persones que volguessen usar de la dita art de menescalia, sens lo qual examen nenguna persona, de qualsevol ley, condició o stament fos, no gosàs ne gose usar de la dita art, romanint la superioritat en tot l'àls, ab tots incidents e emergents, als dits honorables jurats de la dita ciutat.

Presents testimonis foren a les dites coses En Miquel Martí e En Francesch Agut, ciutadans de València.

7 Hemos añadido puntuación y acentuación modernas, y corregido alguna errata. 


\section{EL «LIBRE DE LA MENESCALIA» DE MANUEL DIES}

\section{VI}

1436, marzo 29. Valencia.

Bando del Consell municipal de Valencia obligando a los albéitares de la ciudad a pasar un examen.

Valencia, Arxiu Històric Municipal, Manuals del Consell, A-31, ff. 74v-75.

Publicado por DUALDE PÉREZ, «Notas sobre Albeytería», p. 397; IDEM, «Los exámenes»; e IDEM, Historia de la albeytería, p. 434, § $10^{8}$.

$<$ En el margen izquierdo: > Crida dels menescals.

Ara hoiats què us fan saber lo honorable En Loís Granollés, justícia civil de la ciutat de València:

Que per obviar molts dans que reeben moltes bèsties per mals menescals, hoc en assajen de matar algunes per no entendre ne saber les malalties de aquelles, per benefici de la cosa pública, ell e los honorables jurats de la dita ciutat hajen fet examen de tots los menescals que huy són en la dita ciutat ab alguns metges físichs e cirúrgichs de aquella, e sien stats per aquells elets dos dels dits menescals en majorals e examinadors, e feta certa ordinació que menescal algú no puxa usar de menescalia tro a tant sia examinat, segons en la dita ordinació és largament contengut. Per què lo dit honorable justícia civil, en seguint la dita ordinació, mana ab la present pública crida que de huy avant no sia alguna persona, de qualsevol ley, condició o stament sia, que vulla usar de la dita art de menescalia, <que> use ne gose usar de aquella tro a tant sia examinat; e ladonchs atrobat ésser sufficient, puxa usar de la dita art de menescalia. E açò en pena de cinquanta morabatins d'or applicadors la meytat als cofres del senyor rey e, de la altra meytat, la una part a l'acusador e l'altra al comú de la dita ciutat, e, ultra axò, seran privats perpetualment de la dita art. Per tal, lo dit honorable justícia civil intima e notifica les dites coses a tothom en general e a cascú en special, per ço que per algú o alguns ignorància no puxa ésser al-legada.

En aprés, divenres, comptat .XXX. dels dits mes de març e any mil .CCCC.XXXVI., En Berthomeu Andrés, trompeta e crida públich de la ciutat de València, féu relació ell en lo dia d'ehir haver publicada la damunt dita crida per los lochs e cantonades acostumats de la dita ciutat.

\section{VII}

Mediados s. XV. Barcelona?

Cuestionario práctico para el examen de los albéitares (Tractat de notomia) presente en el Llibre de menescalia de Salvador Vila.

8 Hemos añadido puntuación y acentuación modernas, y corregido alguna errata. 


\section{LLUÍS CIFUENTES Y CARMEL FERRAGUD}

Barcelona, Biblioteca de Catalunya, ms. 423 (mediados s. XV), ff. $57 \mathrm{v}^{\mathrm{a}}-60^{\mathrm{b}}$.

Perquè és de nessesitat, perlem un poch de notomia, axí com se seg<u>ex.

Per donar alguna manera de dochtrina per als menescals, los quals per pocha edat no <en> saben, és de nessesitat fer un petit trachtat de notomia per son recort e avisament a la fi del libre, lo qual serà pertit per capítols axí com se seg<u>ès:

$<1>$ Primo, si·t demanan quina cosa és manescal-lia, respon que és un saber divissit, cor comprèn dues cosses: pràticha e siènsia. $\mathrm{E}$ la pràticha és saber tallar e coura e ligar e perfetament assentar un membre; la siènsia de manescal-lia és conèxer la malaltia.

$<2>\mathrm{Si} \cdot \mathrm{t}$ demanan quina cosa és notomia, respon que notomia és saber donar dreta divisió e determinassió de tots los membres e nirvis del cos del cavall.

$<3>\mathrm{Si} \cdot \mathrm{t}$ demana $<\mathrm{n}>$ quina cosa és vena, respon que vena és vexel de sanch, e pertex del fetge per donar nodriment e vida per tot lo cos vestida de una gonela.

$<4>\mathrm{Si} \cdot \mathrm{t}$ demanan quina cosa és artèria, respon que axò matex, vexel de sanch pus apurada e va pus propinca al cor vestida de dues gonel-les.

$<5>$ Si.t demanan quina cosa és sagnia, respon que sagnia <és $>$ una evacuassió de tot lo cos, e perticul-lar per algun membre achsidentat.

$<6>\mathrm{Si} \cdot \mathrm{t}$ de<ma $>$ nan quans són los membres prinsipals, respon que quatre, ço és, lo cor e lo serveyll e lo fetge e los botons.

$<7>$ Si-t demanan aprés que la sanch és feta dins lo cos quants depertiments fa, respon que quatre.

$<8>\mathrm{Si} \cdot \mathrm{t}$ demanan qualls són, respon que lo primer (que és dita la flor) va al cor, perquè és lo pus prinsipall membre del cos. Lo segon depertiment va per les venes per donar nodriment e vida per tot lo cos. Lo ters depertiment reste en lo fetge - aquesta sanch ja no és tant vermella com l'altra ans és com a fleuma, com per avant direm. Lo quart depertiment va a la melsa; per so és dita la brutedat de les viandes e pot-se provar per ela matexa.

$<9>\mathrm{Si} \cdot \mathrm{t}$ demanan quantes són les sagnies al cos del cavall nessesàries, respon que tretze, onze nessesàries e dues voluntàr<i>es.

$<10>$ Si·t demanen qual-les són les nessesàries, respon que la una és del paladar, la segona és de la lengua, la tersa és de la galta, la quarta és la és [sic] dels lambrots, la sinchena és dels polsos, la sisena és de la taula, la setena és dels pits, la vuytena és de una vena que ha plena mà sobre 1 gonoy, la novena novena $[\mathrm{sic}]$ és de les corones de part de dins, la desena és de les puntes, la onzena és de les cuxes ves la brag<u>erada, la dotzena és de les yllades ho costats, la tretzena és del mascle de la cuha. Les propietats de aq<u>estes <sagnies $>$ són moltes, com per atràs havem dit.

$<11>\mathrm{Si} \cdot \mathrm{t}$ demanan en quantes tes [sic] maneres pot venir mal a les bèsties, respon que en tres, quales són dues naturals e una achsidental.

$<12>\mathrm{Si} \cdot \mathrm{t}$ demanan quantes són les malalties, respon que nou. Si·t demanan quales són, respon que la una és esperavany, alifaf, corbes e corbassa, malendrès, tresfories, agriós, alvaràs e fals corter. 


\section{EL «LIBRE DE LA MENESCALIA» DE MANUEL DIES}

$<13>$ Si·t demanan quants són los nirvis qui sostenen lo cos, respon que deu.

$<14>$ Si.t deman<an> quin depertiment <han $>$ e d'on partexan, respon que del servell e van ha parels, so és, dos als uls, dos a les orelles, e dos als brassos e espatles, dos a les cuxes, e dos per mix [sic] de la escena [sic] fins al cap de la cuha.

$<15>\mathrm{Si} \cdot \mathrm{t}$ demanan <quantes $>$ són les malalties qui breument $\mathrm{a}<\mathrm{n}>$ les bèsties, respon que tres, so és, torsiment de budels e de vexiga e per cuchs. Aquestes duran poch.

$<16>$ Si-t demanan quantes malalties se fan al cap, respon que nou. Si·t demanan quales són, respon que fava e fansela, barbols e peayna, escenèsia [sic], estrangoll, xamora, blancor d'ulls, $<$ e $>$ inflament de cara.

$<17>$ Si.t demanan quantes malalties vénen al col, respon que dues achsidentals e una natural, que és gota qui-s fa en la nuca dell col e fa les bèsties hoenrabirar.

$<18>$ Si.t demanan quantes malalties se fan al peu, respon que tres naturals e altres sobrenaturals; les naturals, rassa per larch, rassa per través e fals corter.

$<19>\mathrm{Si} \cdot \mathrm{t}$ demanen les edats del cavall quantes són, respon que tres. La primera són les fronteres, dues damunt e dues deval, e lansa-les a trenta mesos (que són dos anys e mix). La segona edat lansen altres dues que són aprés tres anys e mix. La tersa, que són les foranes o estremes, lansa-les a quatre anys e mix, e lavós lo cavall és complit e acabat de mudar. Haprés ha de anar dos anys e mix fins a compliment de set anys e lavós les estremes són ap les altres e lo cavall à clos e axí de les altres.

$<20>$ Si-t demanan de les dens, són vuyt e dos escatils e vint-e-quatre cexals [sic].

$<21>$ Si.t demanan dels ossos espondils, respon que vint-e-quatre. La primor d'aquets direm alà hont parlarem de naffras e de ferides.

$<22>\mathrm{Si} \cdot \mathrm{t}$ demanan lo vorm, de què és compost, respon que de les umós, so és, fleuma e còl-lera. E com aquestes dues umós plegades fan algun moviment lo fan per tres raons: la una per refredament; l'altra per mal nodriment de viandes axí com fenal ho erba de prat ho altres semblans en lo ventrel compostas <que > per forsa an de sansar [sic] aquela fleuma que és dita vorm; altra, per estar en companyia de altra bístia que té ag<u>ex [sic] mal. E com lo cavall la lansa per devant fa demostrassió de sal-lut e de la mula per lo contrari, perquè per so com la mula té los seus esturments pus amples detràs que davant.

<23> Si-t demanan lo cavall, si té cal-litat, respon que hoch, segons diu Hypocràs, qui fou lo primer hom que dix en menescal-lia. E diu axí, perlant de les cal-litatats [sic] que, ap tot que los omans e los animals sien divisos, no són divisos sinó per grossa matèria, car tots prenen nodriment dels quatre elaments e són subgechtes a als [sic] signes en què són nats, e per aquesta subgugassió la un és dit colèrich e l'altre sanguini, cor si axí no ere tot $<$ s $>$ seríam de una conplecsió e calitat e lo que seria bo al sanguini tantbé seria bo al flaumàtich. Per $<c ̧ o>$ podem dir que cal-litat és declinassió del sichna qui·l s'enporta a la sua cal-litat, com legim que los signes són divissos de cal-litats, emperò en manescal·lia no·n prenem sinó dues.

$<24>\mathrm{Si} \cdot \mathrm{t}$ demanan quantes malalties véne $<\mathrm{n}>$ al cavall per fleuma, respon que dotze.

$<25>\mathrm{Si} \cdot \mathrm{t}$ demanan quales són, respon que la primera és com la bístiha pert lo mengar, la segona és com inflan los morros, la .III. és com inflan les galtes, la .IIII. és una tos menuda qui ve ap gran secedat [sic], la .V. és com sesfa [sic] cànser en la bocha, la .VI. és com infla la gargamela, la .VII. és com inflan los leus e fan la bístia pantaxar, lo .VIII. és com infla lo col, 


\section{LLUÍS CIFUENTES Y CARMEL FERRAGUD}

lo .VIIII. és com la bístia tors lo morro, lo .X. és com infla la lengua, lo .XI. és com fa massa sal-liva, lo .XII. és com inflan los botons.

Aprés de aver demanda [e] deguda resposta de les coses que pories ésser enterrogat segons acostuman los antichs mestres en exheminar un novisi, e volràs argüir algun bon dichtat per so com legim en tots los dochtós en menescalia que no serian fetes conclusions que primer no fosen fetes qüestions:

Dit avem que los menbres prinsipals són quatre e dir-se pot que no són sinó dos, e $<$ ho $>$ proves per dit del Filòs $<0>f$, e diu que neguna cosa que sie subgeschte a·ltri no porrie ésser dita prinsipal. E, donchs, com lo fetge sie subjechte al cor no pot ésser dit prinsipal, e com se prova que lo fetge sie subgechte al cor per so <com> lo fetge $<$ ha $>$ les les [sic] pus hapurades sanchs que tre tramès [sic] al cor al gran manester totes per so com és prinsipal e nobble menbre del cos. Dels botons direm que no deuen éser $\mathrm{d}<\mathrm{i}>\mathrm{ts}$ prinsipals per so $<\mathrm{com}>$ no són dits prinsipals. Per conseg<u>ent, <serà> feta conclosió que los membres prinsipals no són sinó dos.

\section{VIII}

Segunda mitad del s. XV? Nápoles?

Prólogo del Libre de cavalls según la versión de la traducción francesa del Libre de la menescalia de Manuel Dies.

París, Bibliothèque Nationale, ms. fr. 2002 (s. XV), ff. 1-2.

Publicado por PRÉvOT y RIBÉMONT, Le cheval en France, pp. 343-449.

En nom de Dieu et de la Saincte Trinité, qui est Pere et Filz et Sainct Esperit, tout ung Dieu. Le cheval est moult necessaire a tous chevaliers et gentilzhommez et aussy a hommes d'estat, lesquelx ont a.ffaire les conquestes et les defensions de leur plasse, sans lequelle ne se pult exerciter en armes, car le chevalier ne pult pas aller a piedz pur deffendre et conquester son propre pays, mais plustost vallent moins <que $>$ les vallains et hommes de semblab $<\mathrm{l}>\mathrm{e}$ condicion, lesquelx sont nouris on travail et painne aussy comme leur nature s'adonne a traveller. Se au chevalier et gentilz<hommes $>$ leur nourissement et nature ne s'adonne pas a soustenir telle paine et travail comme font les aultres qui sont acoustumés d'alleir a piedz. Se pour ce, doncques, que les chevaliers doivent aller arméz depuis la teste jusques a piedz, c'est pour deffendre leur peuple de leurs ennemys ainsy comme ceulx qui y sont tenus de les deffendre. Et pour ce que ilz ne pourroient porter sy grant charge de harnois et d'armes ilz penssent aller a piedz [sic], ilz convient qu'ilz allent a cheval. Et mesmement pour fai<r>e differance du chevalier et tiengne l'ordre de chevalerie pour ce, pour les raysons qui anciennement furent

9 Hemos añadido las interpolaciones que hemos considerado necesarias entre paréntesis triangulares y una nueva puntuación, más acorde con el original (véase el Apéndice III) y que obvía los pasajes defectuosamente traducidos. Transcripción revisada sobre el original por Anna Gudayol (Biblioteca de Catalunya). 


\section{EL «LIBRE DE LA MENESCALIA» DE MANUEL DIES}

trouvees, les chevaliers ainsy ont exercité les boins romans et aultres bons chevaliers anciens, et aussy aulcuns de nostre temps. Et pour ce, c'est bien raison qu'il y a grant differance des chevaliers aus gens populaires et que les chevaliers aillent a cheval et les aultres a piedz. Et pour ce, anciennement, voians que la plus necessaire chose estoit au chevalier le roussin, voulurent et ordonnerent que ledit roussin prenist le nom de cheval, c'est assavoir, que on l'apelast cheval, car ainsy comme le fer ne se puelt ouvrer sans feu aussy parellement le fait d'armes ne se puelt exerciter sans cheval. Pour laquelle chose ilz convient necessairement a tous chevaliers et hommes d'armes savoir quatre chose $<s>$ : la premiere sy est bien chevaulchier; la secondre est savoir bien cognoistre la bonne taille du cheval et les bontés et les mauvaistiéz; la tierce est savoir bien tenir et penser; le cheval la quart<e > est savoir cognoistre leurs maladies et inframitéz et de les savoir guerir, car en la guerre ne se truve pas tousjour le mareschal et pouroit advenir telle maladie au cheval que s'il n'estoit bien pensé et mediciné il pourroit le perdre, et si le chevalier pert son cheval en la guerre et il n'en a point d'aultres il pert toute la plus grant parties de l'exercité de la chevalleriez.

Doint je, Mamelz [sic] Diez, maistre d'oustel du moult hault et puissant prinse et victorieulx seigneur Doint Alfons, roy d'Aragon etc, voulu<s $>$ faire ung livre de chevalz pour monstrer aux jeunes chevaliers et gentilzhommes, lesquelx par peu d'aage ne scievent et ne les cognoissent, a ulx je monst $<r>$ eray grant partie de la pratique et de savoir cognoistre les bons chevalx et de leurs infirmités, et grant partiez des remedez que on y doie faire. Lequel livre est departy et mis en .xvii. chappitres.

\section{IX}

ca. 1495. Zaragoza.

Prólogo e introducción de Martín Martínez de Ampiés en su traducción al castellano del Libre de la menescalia de Manuel Dies (según la edición de 1499).

Zaragoza, [Jorge Coci, Leonardo Hutz y Lope Appentegger], 16-X-1499, ff. 5v-6v (Madrid, Biblioteca Nacional, I-674).

Publicado (transcripción paleográfica) por CORTIJO y GóMEZ MORENO, en el ADMYTE, disco 1, núm. $32^{10}$.

Comiença el prólogo de Martín Martínez Dampiez en la traducción por él hecho del libro llamado de albeytaría, compuesto y hecho por el noble Don Manuel Díaz, criado mayordomo del muy poderoso rey Don Alfonso de Aragón, de muy infallible y digna memoria.

\section{PRÓlOGO}

Después de los años <si> quier días antiguos que por Eritonio, hijo de Vulcano, fue inventado y puesto en orden el arte polido y gran exercicio de cavalgar y traher cavallos, sea con

10 Hemos desarrollado las abreviaturas y añadido puntuación y acentuación modernas. 
ruedas si quiere sin ellas, van muy comunes por lo más del mundo entre los reyes y poderosos $<y>$ ahun por medianos y más pequeños, y no sin razón y causas muy grandes; ca éste lo hizo porque pudiesse cubrir el defecto de los serpentinos pies que tenía, viendo el cavallo ser un animal mucho hermoso y más acabado entre quantos viven, sacado el hombre, y porque mirando en cosa tan nueva los de su tiempo dexasen de ver su falta muy grande y él alcançasse con la ligereza y desemboltura siendo cavallero lo que perdía por ser empachado, y no solamente hovo esperança en todo lo dicho empero ahun el conoçimiento mucho que alcançan estos animales con el esfuerço del gran coraçón tanto le plugo, de lo qual Ysidoro, en el libro .XII. ${ }^{11}$, scrive de ellos tales palabras: «Es el cavallo animal despierto, de muy gran biveza, conoçe y siente al cavallero que le va encima, <por> la gana que tiene a las affruentas, quando vencedores en la batalla gran gozo reciben y quando vencidos quedan muy tristes». Pues ahún se puede muy bien dezir que, según vemos por esperiencia, oyendo el son de las trompetas se hazen más bravos para pelear, y entre las turmas y alaridos, quando las boces del cavallero son abivadas, les cresce mucho su coraçón y van encendidos entre las lanças y tan ganosos que sin temor entran por ellas; si cae su dueño, no sólo atiende para que buelva otra vez en silla <sino $>$ que, siendo en tierra, si dañar le quieren, con todas sus fuerças muy bien lo defiende. Tan esforçado y bravo se muestra que si Dios le diera uñas de león apenas otro en<tre $>$ los animales fieros del mundo con él osara tener contienda que no levara toda la mejoría, y ahun con essas armas que tiene, si le encierran entre leones, se pone tan fiero, las crines drechas como erizo tiene las agujas, los ojos bueltos en biva sangre, abre las narizes que dentro parece le arden hachas llenas de fuego, el patear que haze de manos es muy terrible, tanto que han gana más de lo dexar quanta primero le han de vencer. Son muy amigables, lloran sus señores quando los pierden, han sentimiento de las batallas antes que vengan y ahun conoçen unos a otros en el relinchar si quieren reñyr. Algunos dellos huyen de sus madres, según que Plinio, en el .XII. libro ${ }^{12}$, affirma por estas palabras: «Los naturales cavallos de Scicia en las batallas pelean muy fuerte por sus señores, nunca se allegan con sus propias madres para engendrar ni haver con ellas acesso por el verdadero conoçimiento que les da netura». Y porque sería prolixo dezir lo que tantos hablan de sus condiciones, yo proseguiré sin auctoridades a lo començado. Con los cavallos se fazen conquistas, los reynos y tierras son defendidas de los tiranos, y las mujeriles fuerças, muy flacas, por ellos alcançan las de los varones. Y la muy antigua reyna Semíramis, muerto su marido, dissimulaba en forma de hombre, os a cavallo travessar las Yndias fasta donde otros reyes no llegaron, ganó muchas tierras, fundó la ciudad de Babilonia, <y> fue hecha monarcha de aquel imperio. Y las amazones hizieron destragos en Alemaña, en scitas y otras generaciones fasta llegar con Pentesilea en el socorro de los troyanos y fazer daños en las poderosas turmas de los griegos. Pues Alitandre [sic], assí cavallero, la monarchía hovo de las tierras. Y Roma, con ellos, de muy poca ciudad se hizo señora de todo el mundo. Dexadas las guerras, ahun en la paz, las cortes y casas de reyes y otros grandes señores no son abultadas, ni los cavalleros mançebos tienen sin los cavallos el complimiento de su criança.

Por ende, llegando entre mis manos un libro compuesto de albeytería por el noble cavallero mossén Manuel Díaz, hovo por bueno de lo transferir de la catalana lengua en <é>sta de nuestra Hyspaña, porque del trabajo de uno gozen otros muy muchos, assí en la guerra como

\footnotetext{
11 IsIDORO DE SEVILLA, Etimologiae, lib. XII, cap. I, § 43.

12 Corresponde a CAYO PLINIO EL VIEJO, Historia Naturalis, lib. VIII, cap. LXIV, donde no lo dice «por estas palabras» sino con otras.
} 


\section{EL «LIBRE DE LA MENESCALIA» DE MANUEL DIES}

en reposo, y porque vea qualquier cavallero que es obligado saber quatro cosas de los cavallos: la primera, deve <saber> muy bien cavalgar; y la segunda, conoscer el talle, bondades y vicios en el cavallo; es la tercera saberlo pensar; la quarta, conoscer todas sus dolencias y curar aquellas, porque en las guerras siempre no pueden haver albéytares y en tal tiempo y parte puede venir la dolencia que si no saben dar el remedio se perdería, y el cavallero es despojado del exercicio mayor que tiene. Pues por lo dicho, y más que se dexa para el hábito de cavallería, es muy necessario tal arte saber y deve ser ella mucho preciada por todos aquellos que quieren tratar en los cavallos, de la qual tomen la buena sentencia de quien le compuso y no mi habla más ordenada, en que si hallaren algunos defectos, no los causó mi voluntad, mas pida perdón mi poco saber.

\section{INTRODUCCIÓN}

Fueron ordenados los presentes dos libros por este noble mossén Manuel, y el primero, que trata de los cavallos, fue repartido en .XVII. partes principales. Es la primera, del engendrar o creación de los cavallos. La segunda trata de la manera de ser domados. La tercera habla $<$ de $>$ cómo se deve tener y pensar el c<av>allo de tres años fasta en seys. La quarta será en qué manera la yerba se deve dar y en qué tiempo al cavallo potro y al que passa de cin<co $>$ años. La .V. trata de la hermosura <de> los cavallos y qué bondades han de tener para ser buenos. La .VI. demuestra de conoscer las partes feas de qualquier cavallo y sus malos vicios, por que mejor el cavallero se pueda guardar de ser engañado. La .VII. trata <de> cómo se les deve hazer el pienso assí en la guerra como en la paz. La .VIII. trata de la diversidad y conoscimiento de todos los pelos si quier colores. La .IX. demuestra los buenos y malos señales blancos que pueden tener muchos cavallos. La .X. dize de los repelos o remolinos que bien o mal señalan. La .XI. habla de la manera del enfrenar y poner en boca los cavallos fuertes y bocamuelles y por qualquier forma que no se trayan bien a la mano. La .XII. trata por extenso de las dolencias que son naturales y de las curas y buenos remedios. La .XIII. trata de las dolencias que suelen venir por accidente y la manera de hazer las curas. La .XIIII. pone las sangrías, quantas se fazen y por qué razón si quier causas. La .XV. trata del mudar o echar de todos los dientes, y cómo pueden ser los cavallos mejor conoscidos si fueren potros o ya muy viejos. La .XVI. habla de cómo les deven sacar fuera los colmillos y del adobo para las bocas. La .XVII. y postrimera pone la forma como los cavallos deven ser castrados quando son muleros. Las quales partes son repartidas en muchas partículas como se demuestran por que ya mejor sean entendidas y más presto vistas y halladas según la materia que a cada uno fuere necessaria y provechosa. En la .XI. parte, que trata del enfrenar de los cavallos, hallaran pintados algunos muessos según las bocas fuertes o blandas, empero por esso, después que hovieren aquellos provado, si algun cavallo havrá tal defecto que no se vence por tal manera, prueven los otros, porque en los muchos cavallos se hallan muchos defectos y es forçado que los remedios sean diversos. Pone después el segundo libro, que trata <de las $>$ mulas, como se muestra por su prólogo y introducción, a cartas LII. 